\title{
WestVirginiaUniversity
}

THE RESEARCH REPOSITORY @ WVU

Graduate Theses, Dissertations, and Problem Reports

2009

\section{The effects of Active Living Every Day Online on physical activity}

Amy M. Sidwell

West Virginia University

Follow this and additional works at: https://researchrepository.wvu.edu/etd

\section{Recommended Citation}

Sidwell, Amy M., "The effects of Active Living Every Day Online on physical activity" (2009). Graduate Theses, Dissertations, and Problem Reports. 2846.

https://researchrepository.wvu.edu/etd/2846

This Dissertation is protected by copyright and/or related rights. It has been brought to you by the The Research Repository @ WVU with permission from the rights-holder(s). You are free to use this Dissertation in any way that is permitted by the copyright and related rights legislation that applies to your use. For other uses you must obtain permission from the rights-holder(s) directly, unless additional rights are indicated by a Creative Commons license in the record and/ or on the work itself. This Dissertation has been accepted for inclusion in WVU Graduate Theses, Dissertations, and Problem Reports collection by an authorized administrator of The Research Repository @ WVU.

For more information, please contact researchrepository@mail.wvu.edu. 
The Effects of Active Living Every Day Online on Physical Activity

Amy M. Sidwell

\author{
Dissertation submitted to the \\ College of Physical Activity and Sport Sciences \\ at West Virginia University \\ in partial fulfillment of the requirements \\ for the degree of \\ Doctor of Philosophy \\ in \\ Kinesiology with an emphasis in \\ Physical Education Teacher Education \\ Sean M. Bulger, Ed.D., Chair \\ Reagan P. Curtis, Ph.D. \\ Andrew B. Hawkins, Ph.D. \\ Lynn D. Housner, Ph.D. \\ Richard T. Walls, Ph.D. \\ Robert L. Wiegand, Ed.D. \\ Department of Coaching and Teaching Studies
}

Morgantown, WV

2009

Keywords: Active Living Every Day Online, physical activity, online learning

Copyright 2009 Amy M. Sidwell 


\begin{abstract}
The Effects of Active Living Every Day Online on Physical Activity
\end{abstract}

Amy M. Sidwell

The purpose of this study was to examine the effects of a 14-week intervention based on Active Living Every Day (ALED) Online. Outcomes of the 14-week online program and the process of delivering the program were analyzed. Outcome considerations included: whether ALED Online increased physical activity among participants (as measured through step counts), whether physiological changes (cholesterol and body mass index) were apparent throughout the intervention, and whether participants progressed or regressed through the Stages of Change (SOC). Process measures included examining the nature of retention of participants in the program and the quality of participants' responses to the "Life Assignments" homework component of ALED Online. This study used a quantitative/qualitative mixed methodology. Statistical analyses, qualitative analyses, and an integrated analysis of the mixed methodology are provided. There were no overall statistically significant intervention effects for the group at large from $\mathrm{O}_{1}$ to $\mathrm{O}_{3}$ $[F(10,3)=.626, p=.749$, n.s. $]$. However, there were overall statistically significant intervention effects for those who completed all four testing occasions (research adherents) $[\mathrm{F}(1,5)=2.26, \mathrm{p}=.021]$. Research adherents saw improvements in HDL cholesterol, LDL cholesterol, and SOC. Seven themes (Rationalization, Ease of Use, Thoughts, Behaviors, Time, Facilitation, and Accountability) elucidated typical participants' experiences with the program. Drop-outs', mid-achievers', and highachievers' results are highlighted. 
For Todd, Olivia, and Elizabeth 


\section{ACKNOWLEDGMENTS}

I'd like to recognize the contributions of many people who have been supportive throughout my course of study at West Virginia University.

My committee deserves special thanks. Dr. Sean Bulger spent countless hours meeting with me, meeting with participants, making suggestions, and answering email at all hours. Dr. Reagan Curtis, Dr. Andrew Hawkins, Dr. Lynn Housner, Dr. Richard Walls, and Dr. Robert Wiegand have been especially kind in helping plan both my research and my doctoral plan of study. Dr. Andrew Ostrow also deserves thanks for making editorial suggestions for my prospectus.

I'd also like to thank those who helped secure funding for this research project. Dr. Dana Brooks, Dean of West Virginia University's College of Physical Activity and Sport Sciences, approved funding through the College's Internal Grant Program. Dr. Jonathan Cumming, Vice President of Graduate Education, provided funding through the West Virginia University Dissertation Fellowship. This research received in-kind funding through Active Living Partners. I'd like to thank Bhibha Das at Active Living Partners for her support, instruction, and advice over the past year.

My fellow doctoral students also deserve recognition for their encouragement. Amanda Metcalf has been a true friend over the course of our program. I'd also like to thank Jack Sager, Susan Ross, and Jason Langley for being such good listeners. I thank Kacey DiGiacinto for helping distribute pedometers.

From the WVU Coliseum, I'd like to extend a sincere thanks to Carol Straight, Theresa Scafella, Robin McKinney, Debra Hardesty, Tracy Wheeler, Sharon Sisler, Kim Cameon, Sherry Binion, and Joanne Pollitt.

This research project would not have been possible without the cooperation of the participants. I thank each one of them for their time and effort as they matriculated through the Active Living Every Day Online research project.

Finally, I'd like to thank my family for just about everything. It would have been nearly impossible for a girl from Edinboro Mobile Home Village to succeed without their influence. 


\section{TABLE OF CONTENTS}

Page \#

CHAPTER 1 Introduction and Statement of the Problem ..............................................1

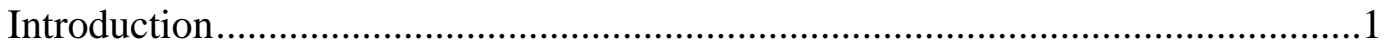

Lifestyle Modification and the Cooper Institute........................................1

Transtheoretical Model and Stages of Change Construct..........................3

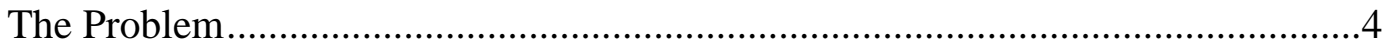

Statement of the Problem......................................................................4

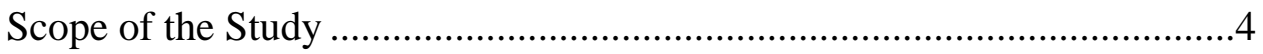

Basic Assumptions .....................................................................6

Definition of Terms..........................................................................

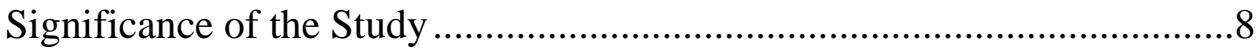

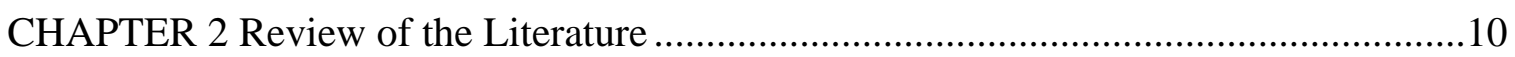

Cardiovascular Health and Physical Activity ...................................................11

Behavior Change and Physical Activity ..........................................................

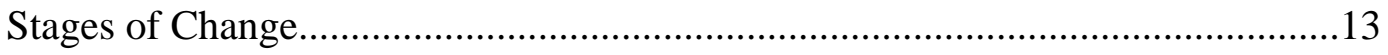

Distance Learning in Physical Activity Promotion .............................................16

Active Living Every Day .....................................................................18

Summary of Review of the Literature .......................................................21

Research Hypotheses .............................................................................23

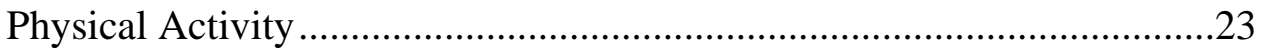

Physiological Measures ..............................................................23

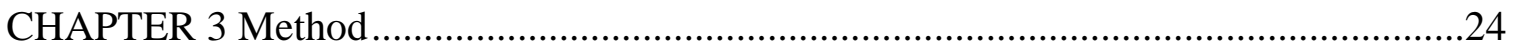

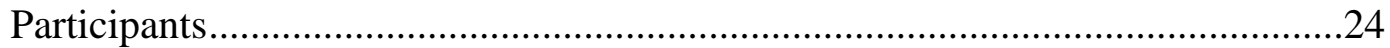




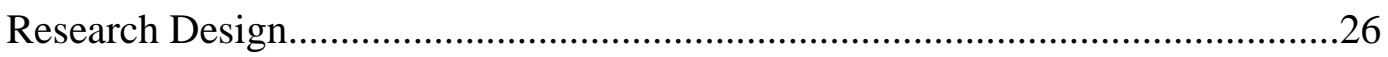

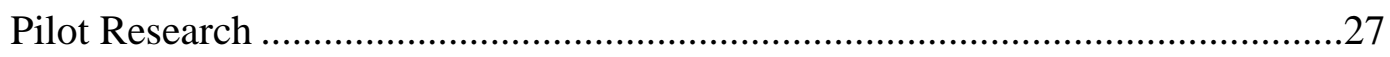

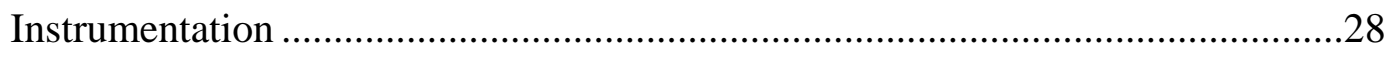

Physical Activity Instruments ...................................................................28

Physical Activity Readiness Questionnaire ....................................28

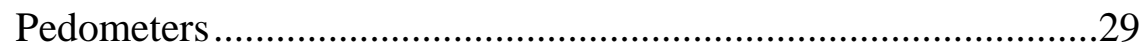

Stage of Readiness to Change Decision Tree ..................................30

Physiological Instruments.......................................................................

Lipid Panel Blood Analysis ..............................................................31

Body Mass Index ………………………......................................

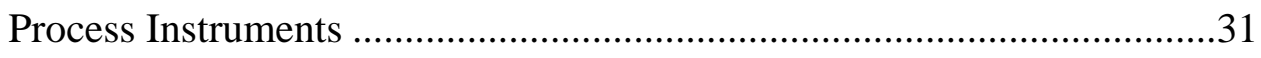

Life Assignments Tracking..............................................................31

Semi-Structured Interview .............................................................32

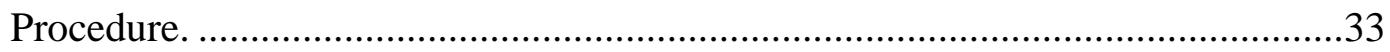

Researcher Training .............................................................................33

ALED Director and Facilitator Training.........................................33

Role of the Facilitator .....................................................................33

Qualitative Methods......................................................................34

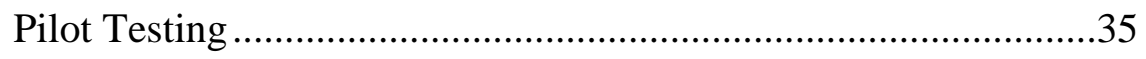

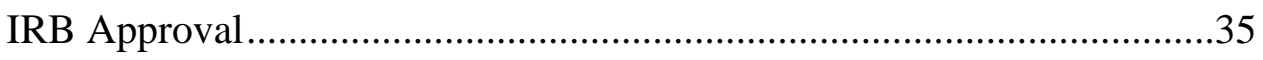

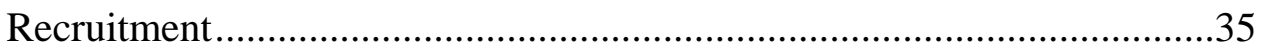

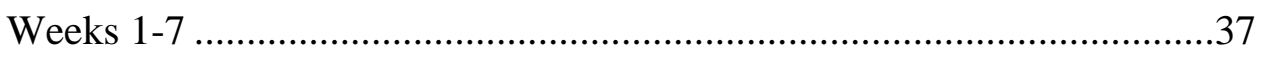

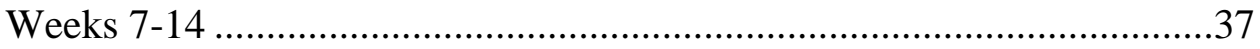




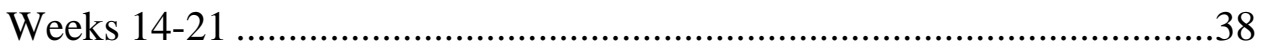

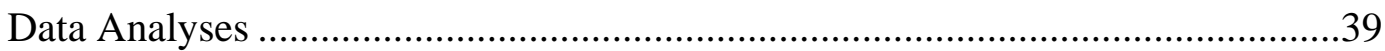

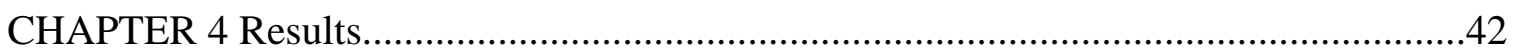

Analyses of Descriptive Statistics........................................................................42

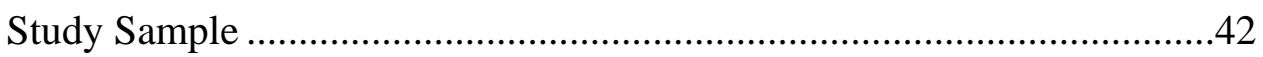

Completion of Active Living Every Day Life Assignments .......................43

Quantitative Analyses .....................................................................................43

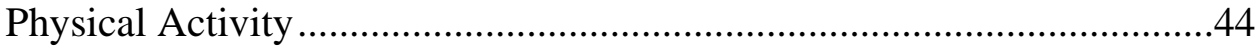

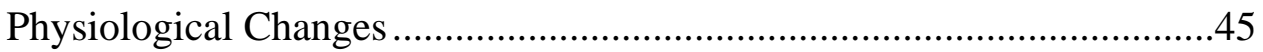

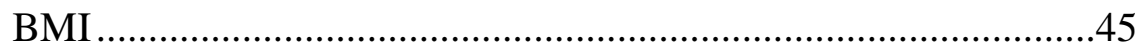

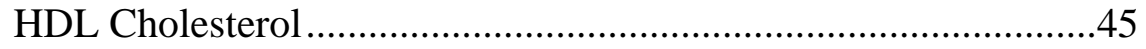

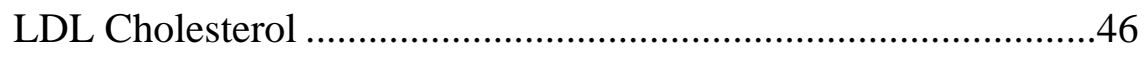

Stage of Readiness to Change...................................................................46

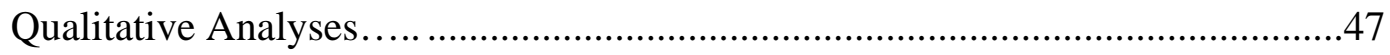

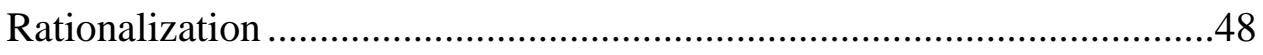

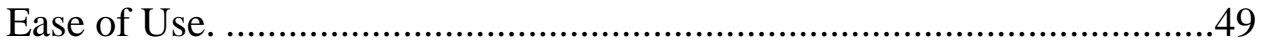

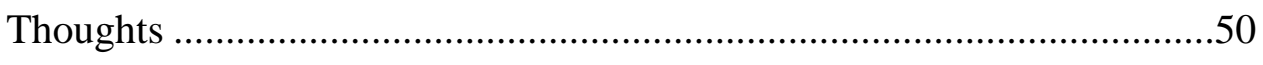

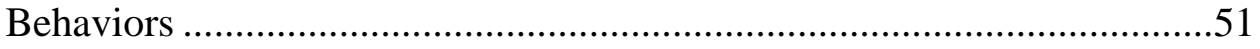

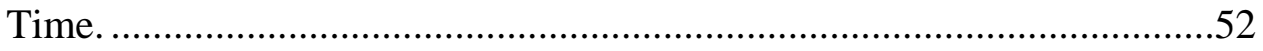

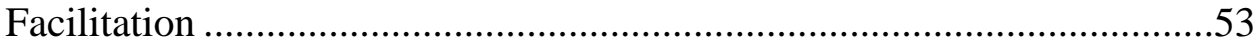

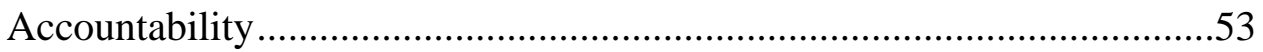

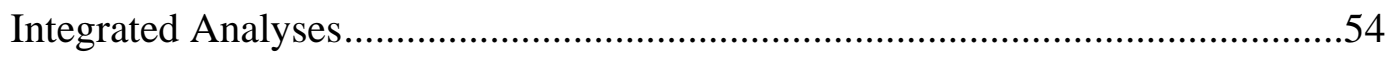

High-Achievers .........................................................................................55 


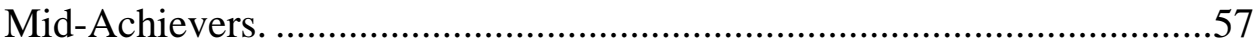

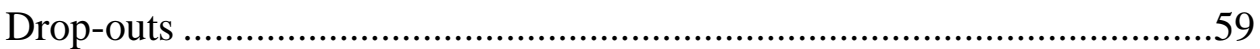

Summary of Integrated Analyses ...................................................60

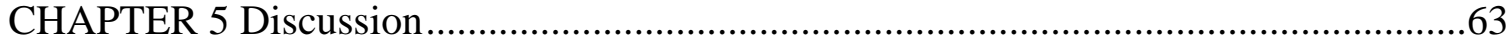

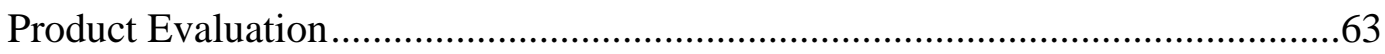

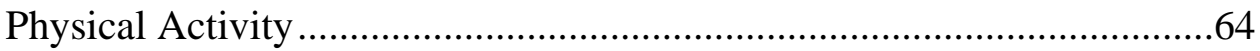

Physiological Indicators ............................................................65

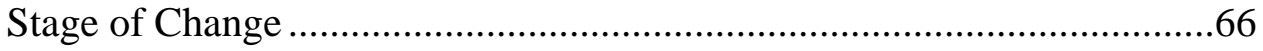

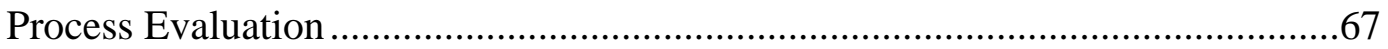

Needs Assessment and Planning......................................................68

Program Implementation ..............................................................69

Program Evaluation ................................................................ 71

Strengths, Limitations, and Future Directions ................................................74

Strengths of the Research.................................................................74

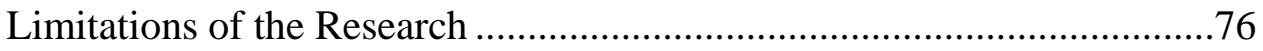

Suggestions for Future Directions ....................................................77

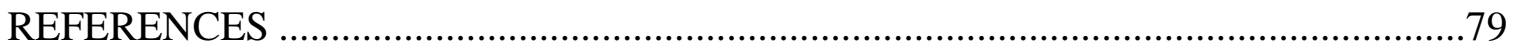

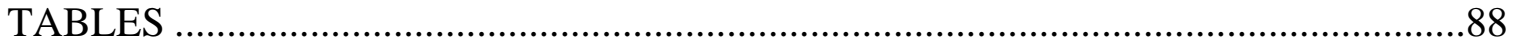

Table 1 High-Achievers’ Averages O1 through O4 ...........................................88

Table 2 Mid-Achievers’ Averages O1 through O3............................................89

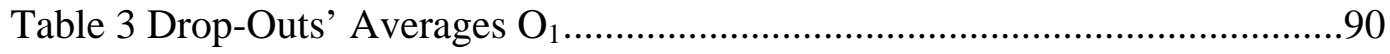

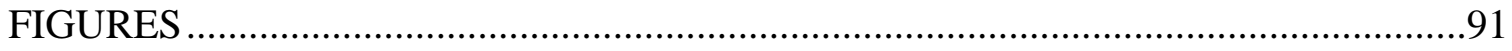

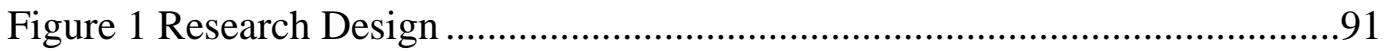


Figure 2 Number of Participants with Step Count Data ...................................92

Figure 3 HDL Cholesterol for Research Adherents $\mathrm{O}_{1}$ through $\mathrm{O}_{4}$....................93

Figure 4 LDL Cholesterol for Research AdherentsO $\mathrm{O}_{1}$ through $\mathrm{O}_{4} \ldots \ldots \ldots \ldots \ldots \ldots \ldots . . . . . . .94$

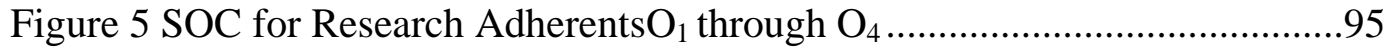

APPENDIX A Physical Activity Recall Questionnaire (PAR-Q) .................................96

APPENDIX B Stage of Change Decision Tree ......................................................97

APPENDIX C Demographic Information Sheet .....................................................98

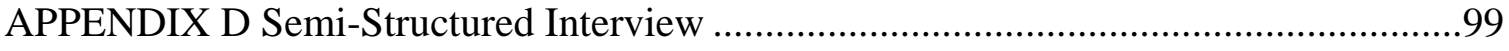

APPENDIX E Control Condition Questionnaire ......................................................100

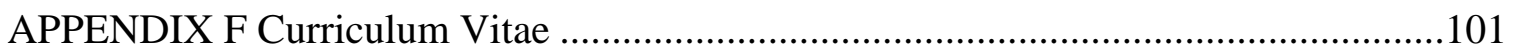




\section{CHAPTER 1}

\section{INTRODUCTION AND STATEMENT OF THE PROBLEM}

Lifestyle factors such as obesity and physical inactivity are often cited as risk factors for a number of diseases and conditions. Many studies indicate that obesity increases a person's risk for coronary heart disease (National Institutes of Health National Heart Lung and Blood Institute, 1998; Strandberg, Tilvis, Pitkala, \& Miettinen, 2006) and diabetes (American Diabetes Association, 2007; Blair \& Church, 2004; Foreyt \& Poston, 1999). Obesity and physical inactivity have similar physiological health consequences (Blair \& Church, 2004). Research-based behavioral interventions are often developed in order to mitigate the negative effects of physiological changes related to physical inactivity.

Kenneth Cooper, President and Founder of The Cooper Aerobics Center, wrote, “...I used to think that if I told people they needed to exercise, they would do it...But becoming, and staying active takes time, effort, and most important, the development of special lifestyle skills" (Blair, Dunn, Marcus, Carpenter, \& Jaret, 2001, p. vii). Indeed, being physically active requires a commitment on the part of the individual to invest the time and effort to develop lifestyle skills. These skills include goal-setting, time management, and identifying one's personal readiness to make behavior change.

\section{Lifestyle Modification and the Cooper Institute}

In order to mitigate risk factors for cardiovascular disease or diabetes, lifestyle modification programs are often beneficial. Providing lifestyle modification programs in order to increase physical activity is a promising approach for reducing risk factors (Foreyt \& Poston, 1999). One organization that has provided lifestyle modification 
programs is the Cooper Institute. The Cooper Institute is recognized world-wide as a leader in fitness. The organization provides programs for a variety of health topics, including physical activity, nutrition, and lifestyle management.

Active Living Every Day (ALED) is the Cooper Institute's "cornerstone course." The course focuses on getting sedentary people to be active and to maintain physical activity throughout their lives. This course is delivered by worksites, colleges, community health programs, and hospitals (Cooper Institute, n.d.). Its purpose is to assist participants with finding ways to incorporate physical activity throughout their daily lives. This course may be delivered by a provider, or may be done as a self-study course. As part of the self-study option, participants may purchase a book and/or utilize the online support called ALED Online provided by the Cooper Institute and facilitated by Human Kinetics.

The efficacy of the traditional 20-week course has been documented (Dunn et al., 1998; Wilcox et al., 2006), but the efficacy of the shortened online intervention has only been documented in one study (Carr et al., 2008). Dunn et al. (1998) found that a group enrolled in a healthy lifestyles course that was the pre-cursor to ALED at the Cooper Institute improved their levels of physical activity from baseline to 24 months. Wilcox et al. (2006) found that the 20 -week ALED program could be implemented successfully in community settings with diverse populations. Carr et al. (2008) found that participants enrolled in an internet-delivered, 16-week ALED course also increased physical activity and improved cardiovascular disease risk factors. 
Transtheoretical Model and Stages of Change Construct

The Cooper Institute developed Active Living Every Day using James

Prochaska's Transtheoretical Model with the Stages of Change (SOC) construct. The Transtheoretical Model is an explanatory model which describes intentions or readiness to make behavior change (Prochaska \& Marcus, 1994). It is a model comprised of four dimensions: stages of change, processes of change, efficacy, and decisional balance (Prochaska \& Velicer, 1997). The SOC construct within the Transtheoretical Model is comprised of five stages, including Pre-contemplation, Contemplation, Preparation, Action, and Maintenance. Prochaska asserts that as people are making behavioral change, they progress through these five stages (Prochaska \& Marcus, 1994).

The SOC construct has been used frequently to address multiple health behavior risks, such as smoking, poor nutritional choices, developing skin cancer, and the determinants toward seeking mammograms (Prochaska et al., 2005). There has also been a great deal of research using the Transtheoretical Model, the SOC construct, and physical activity (Jackson, Asimakopoulou, \& Scammell, 2007; Lippke \& Plotnikoff, 2006; Miilunpalo, Nupponen, Laitakari, Marttila, \& Paronen, 2000). Jackson, et al. found that using the Transtheoretical Model with the SOC construct was effective at prompting increases in physical activity (2007). Lippke and Plotnikoff (2006) found the Transtheoretical Model to be a utilitarian means for targeting stage-based behaviors.

Despite the research on SOC and physical activity, there have been no studies examining whether stage change occurs for participants using ALED Online. Therefore, the purposes of this proposed study were to determine the following: (1) Does ALED Online increase physical activity? (2) What physiological changes are evident prior to 
the intervention, during the intervention, and after the intervention has been completed? and, (3) Do participants in ALED Online progress or regress through the Stages of Change?

The Problem

\section{Statement of the Problem}

When delivered in a traditional classroom format, ALED increases physical activity (Wilcox et al., 2006). However, there is limited data to support the efficacy of the online component of the program. Further, the efficacy of ALED Online and its relationship to SOC has not been fully documented.

The purpose of this study was to examine the effects of a 14-week intervention based on ALED Online. Specifically, the outcomes of the program and the process of delivering the program were explored. Outcome considerations included: whether ALED Online increased physical activity, whether physiological changes were apparent throughout the intervention and at follow-up, and whether participants in ALED Online progressed or regressed through the SOC.

Scope of the Study

This study used a mixed method, quantitative/qualitative research design framework to examine the effects of a 14-week intervention based on ALED Online. The ALED course is typically delivered as a 20-week course, but the Cooper Institute endorses a modified curriculum lasting 14 weeks in duration. For the purposes of this study, the 14-week program was chosen.

Twenty-one adult participants were recruited through a variety of communitybased programs, employee wellness programs, and media outlets. Although the potential 
participants may have been sedentary, they could not have medical conditions that would have prohibited them from engaging in moderate intensity physical activity. Each participant submitted a Physical Activity Readiness Questionnaire (PAR-Q) (Canadian Society for Exercise Physiology, 1994), indicating their ability or inability to participate in physical activity. Participants were required to be able to ambulate independently, and (after instruction) have the ability to wear a pedometer correctly.

Repeated physiological and physical activity measures were collected at four points throughout the study to determine whether there were time differences that could be attributed to the intervention. On four occasions, the following were collected: highdensity lipoprotein cholesterol (HDL), low-density lipoprotein cholesterol (LDL), Body Mass Index (BMI), current SOC, and physical activity estimates (measured through step counts).

The purposes of the multivariate repeated measures were to determine: (1) whether the group increased physical activity, made stage change progression, and improved physiological measures from baseline to the end of the 14 week intervention, and (2) whether the group had physiological or physical activity changes 7 weeks after completing the 14-week intervention.

To determine the effect of the intervention over time, the independent variable was time of assessment. The dependent variables measured on four occasions included: HDL, LDL, BMI, SOC, and physical activity estimates. Lipid panel blood analyses were used to examine measures of HDL and LDL. Additionally, height and weight were measured to determine BMI. Participants wore pedometers seven consecutive days prior to implementation of the intervention, seven consecutive days at week 7 of the 
intervention, seven consecutive days at week 14 of the intervention, and then seven consecutive days seven weeks after the completion of the intervention. Furthermore, participants completed the "Identifying Your Readiness to Change" activity in ALED (Blair et al., 2001) to document their current SOC on four occasions. Life Assignments and semi-structured interview transcripts were examined in order to examine the nature of retention of participants in the program and the process of delivering ALED Online.

\section{Basic Assumptions}

1. Pedometers are valid and reliable instruments for measuring physical activity. A number of studies indicate that various brands of pedometers may be valid measures for step physical activity (Bassett et al., 1996; Bassett, Cureton, \& Ainsworth, 2000; Nelson, Leenders, \& Sherman, 1998). A number of studies have found pedometers are reliable for physical activity research (Bassett et al., 1996; Tryon, Pinto, \& Morrison, 1991). And, wearing a pedometer for just 5 to 6 days is long enough to obtain data that represents "usual" physical activity (Gretebeck \& Montoye, 1992).

2. Assessing a participant's SOC is an important consideration for implementing ALED. According to the ALED Facilitator Guide, participants will apply the material presented in the ALED program differently based on their stage of readiness (Active Living Partners, 2002). As an instructor, a variety of key teaching points are necessary for targeting messages to participants in different stages (Active Living Partners, 2002).

3. Participants in the study will increase their physical activity. According to a study by Wilcox et al. (2006), when ALED is implemented in a diverse setting by 
trained staff, participants see an increase in physical activity and a decrease in BMI.

4. ALED's Modified 14-week course provides a sufficient amount of time for participants to make behavioral change and realize progression in stages of change. Currently, there is only limited empirical evidence to suggest a 14-week program is as efficacious as the 20 -week program. However, Active Living Partners endorses the 14-week modified curriculum.

5. Participants complete activities in a timely manner. Facilitators can use the Facilitator Class Management menu to view participants' online activities. If activities are not completed in a timely manner, the facilitator has the ability to send an email prompt to the participants.

\section{Definition of Terms}

Transtheoretical Model is a model comprised of four dimensions: stages of change, processes of change, efficacy, and decisional balance (Prochaska \& Velicer, 1997).

Stages of Change (SOC) indicate the steps people progress through as they make behavioral changes. These include: precontemplation, contemplation, preparation, action, and maintenance (Pro-Change Behavior Systems, 2007).

Pre-contemplation is often defined as a person having no intention to increase moderate-intensity physical activity (Blair et al., 2001).

Contemplation is described as thinking about physical activity, but not doing it (Blair et al., 2001). 
Preparation is described as accumulating moderate-intensity physical activity less than 30 minutes at a time on at least one day per week. (Blair et al., 2001).

Action is described as accumulating moderate-intensity physical activity on most days of the week consistently, but for less than six months (Blair et al., 2001).

Maintenance is described as accumulating at least 30 minutes of moderateintensity physical activity on most days per week, and this behavior has been maintained for six months or more (Blair, Dunn, Marcus, Carpenter, \& Jaret, 2001).

Significance of the Study

Currently, the efficacy of ALED Online as a behavioral intervention to increase physical activity has been documented only once (Carr et al., 2008). Furthermore, the efficacy of Active Living Every Day Online and its relationship to SOC have not been documented. The present study was developed to determine whether ALED Online is an effective intervention for changing physical activity, blood lipid profile, BMI, and/or SOC.

The use of an online intervention to promote physical activity represents a departure from traditional school-based or community-based physical activity programs. This departure may be a promising approach for promoting physical activity behaviors in certain instances where social, individual, or environmental factors make face-to-face interaction less desirable. An online format may mitigate barriers which inhibit participation in traditional instructional programs. Those barriers often include: time conflicts, travel to a site, apprehension with fitness facilities, and costs. This course was delivered asynchronously when participants had the time to log-on. This approach may be attractive for participants who view travel to a class as a barrier to participation in an 
intervention. ALED Online is also an attractive option for people who are uncomfortable exercising in traditional settings such as gyms and fitness facilities.

With this program, people are free to incorporate physical activity into their activities of daily living. Some participants may have recognized that the financial costs for participation in this study were minimal when compared to monetary costs for health club or gym memberships. For people who are comfortable using the internet, the ALED Online mode of delivery may eliminate traditional barriers to physical activity and encourage accumulating moderate amounts of physical activity into their daily routines. 


\section{CHAPTER 2}

\section{REVIEW OF THE LITERATURE}

Physical activity is a key determinant of health. A lack of physical activity can often predict risk factors and emerging disease patterns for an individual. As technological advances have made modern life easier, people have become more sedentary. According to Blair and Church (2004), "The modern living environment in developed countries is characterized by low daily energy expenditure...The result is a rightward skewing of the body mass index (BMI) distribution and an increasing prevalence of obesity" (p. 1232).

Obesity and physical inactivity have similar physiological health consequences (Blair \& Church, 2004). There is strong clinical evidence that obesity is linked to cardiovascular disease (Hubert et al., 2009; Strandberg et al., 2006). Researchers in physical activity have an obligation to explore the link between cardiovascular health and physical activity and implications for promoting behavior change among sedentary people.

Traditional physical activity programs (such as school-based physical education programs, health club participation, or organized sports) have produced feelings of dread and alienation for some participants (Sykes \& McPhail, 2008). An alternative approach to physical activity promotion for those who feel disenfranchised by traditional physical activity programs could be online learning. Therefore, the purpose of this chapter is to review literature in the areas of cardiovascular health and physical activity, behavior change and physical activity, Stages of Change (SOC), distance learning in physical 
activity, and Active Living Every Day (ALED). Additionally, a summary of the review of literature will be provided.

Cardiovascular Health and Physical Activity

The costs of physical inactivity are enormous in regard to monetary losses, medical claims, and deaths. Physical inactivity costs the average American $\$ 275$ per person (Chenoweth, 2001), while physical inactivity costs the average Michigan resident \$1175 per year (Chenoweth, DeJong, Sheppard, \& Lieber, 2003). In a study that estimated the medical costs of physical inactivity among 1.5 million participants in Blue Cross Blue Shield of Minnesota, costs to the insurer for heart disease, alone, were $\$ 35.3$ million (Garrett, Brasure, Schmitz, Schultz, \& Huber, 2004). Interestingly, the obesity risk factor was omitted from this estimate, as the focus was on costs of disease related simply to physical inactivity.

Physical inactivity is implicated in the development of preventable lifestyle diseases, such as cardiovascular disease. Sallis and Owen (1999) contend that the effects of being physically inactive can be described in terms of estimating the number of deaths attributed to physical inactivity. In West Virginia, for example, diseases of the heart were responsible for 26,200 years of life lost, and accounted for $26.6 \%$ of all deaths in the state during the year 2005 (West Virginia Department of Health and Human Resources, 2005).

The process of developing cardiovascular disease leading to death can be attributed to the build-up of plaque within blood vessels. When blood flow to the heart is blocked, coronary heart disease develops. There is a greater risk of developing coronary 
heart disease among people who are physically inactive or among those with low levels of cardio-respiratory fitness (Janssen, 2007).

To some extent, cardiovascular disease is also linked to BMI. In an 8-year study of 13,230 healthy, non-smoking men, researchers found that an increase in BMI greater than or equal to $2.0 \mathrm{~kg} / \mathrm{m}^{2}$ was associated with an increase in cardiovascular disease. It was somewhat confounding, however, that the researchers also found an increase in cardiovascular risk among men who lost weight (Bowman, Kurth, Sesso, Manson, \& Gaziano, 2007).

Fortunately, evidence suggests that physical activity is strong protective factor for preventing coronary heart disease (Sallis \& Owen, 1999). As expected, “...the most active individuals have, on average, the lowest risk of developing coronary heart disease" (Janssen, 2007, p. 163). The American College of Sports Medicine (2000) wrote that regular physical activity produces reductions in coronary artery disease risk factors, while increasing high-density lipoprotein cholesterol (HDL), decreasing triglycerides, and reducing total body fat. Because physical activity increases HDL, the risk of cardiovascular disease is reduced (Sallis \& Owen, 1999).

\section{Behavior Change and Physical Activity}

In order to mitigate risk factors for cardiovascular disease, a behavioral approach to increasing physical activity could be considered. Pate (2007) asserted, “...most of the initial interest of behavioral scientists was focused on the learning of motor skills and enhancement of performance in sports, neither of which relates to directly to the effects of physical activity on health" (p. 26). He wrote that behavioral sciences have conducted physical activity interventions with individuals, groups, and communities, and what 
seems clear is that there are a number of social, personal, and environmental factors that relate to the adoption of consistent physical activity behaviors.

In a study of obese, type 2 diabetics (Foreyt \& Poston, 1999), researchers found that behavioral change could be facilitated through lifestyle modification programs. These programs included discussion with patients about the benefits of physical activity and how symptoms of diabetes could be mitigated by including moderate amounts of physical activity into a patient's life. Researchers in this study acknowledged the role of behavioral modification in order to get patients to use self-monitoring, goal setting, and coping skills.

In order to produce increases in physical activity and reduction of cardiovascular disease risk factors, moderate-intensity lifestyle programs can be effective, even when compared to structured exercise programs. In a randomized trial by Dunn et al. (1999) two cohorts of participants were enrolled into either a lifestyle program or a structured exercise program. Both programs were based on behavioral modification tools, including weekly home assignments, regular assessments, and newsletters. Results of this study demonstrated that both groups increased their overall amounts and levels of physical activity and reduced their body fat. However, the lifestyle group did not see improvement in high-density lipoprotein (HDL) or low-density lipoprotein (LDL) cholesterol, while the structured exercise group did see those improvements.

\section{Stages of Change}

Many behavioral change programs are based on James Prochaska's Transtheoretical Model and the SOC construct (Prochaska \& Marcus, 1994). The Transtheoretical Model is an explanatory model that describes intentions or readiness to 
make behavior change (Prochaska \& Marcus, 1994; Prochaska, 2007). It is a model comprised of four dimensions: SOC, processes of change, efficacy, and decisional balance (Prochaska \& Velicer, 1997). The SOC construct within the Transtheoretical Model is comprised of five stages, including pre-contemplation, contemplation, preparation, action, and maintenance. Prochaska asserts that as people are making behavioral change, they progress through five stages (Prochaska \& Marcus, 1994).

A number of researchers have used the Transtheoretical Model and SOC in interventions ranging from smoking cessation (Prochaska et al., 2008) to family caregiving (Tung \& Gillett, 2004) to workplace programs (Prochaska, 2007). For the purposes of this literature review, those studies focusing on the use of the Transtheorectical Model and SOC in relation to physical activity will be highlighted.

Two international studies using college students have described the use of the Transtheorectical Model and SOC with physical activity. In a British study of approximately 400 undergraduate students, researchers found a high, positive relationship between SOC and physical activity (Daley \& Duda, 2006). However, because the number of pre-contemplators in the study was small, the researchers chose to combine participants who were in the pre-contemplation and contemplation stages into one group, and it is possible doing so affected the findings. What seems to be evident is that for participants in the lower SOC, self-determination was also found to be lower (Daley \& Duda, 2006). In a study of 228 undergraduate students from South Korea, researchers found Transtheorectical Model constructs such as behavioral processes, self-efficacy and cognitive processes were significantly correlated with the stages of exercise behavior (Kim, 2006). 
In order to determine whether building intervention programs around the Transtheoretical Model is effective, Lippke and Plotnikoff (2006) presented crosssectional data from a longitudinal study using multiple theoretical domains. A random sample of approximately 1600 adults in Canada was surveyed about their physical activity habits and SOC. Demographic information collected by the researchers included gender, marital status, education, employment status, and BMI. Those individuals in the pre-contemplation stage reported lower levels of self-efficacy around physical activity than individuals in other stages. But, participants in other stages reported better selfefficacy.

It is reasonable to make the connection between low self-efficacy and lower levels of physical activity. In a qualitative study conducted by Canadian researchers, 16 participants were interviewed in order to understand factors that discourage people who are both obese and who have low incomes from accessing weight loss services. Decisions to participate in physical activity were made gradually, and were based on complex factors that often related to a participant's SOC. Results indicated that participants' "disincentives to action" were based on triggers such as embarrassment, fear of humiliation, and previous bad experiences (Tod, 2004). As a result, it is important to consider people's stage of readiness to change, and whether potential participants in physical activity promotion programs bring with them pre-existing psychological disincentives to action.

According to Lippke and Plotnikoff (2006), “...physical activity interventions should be tailored to stage of readiness..." (p. 300). A meta-analysis of 57 studies supports this claim (Noar, Benac, \& Harris, 2007). When comparing disparate programs, 
those that use tailoring around self-efficacy, and programs that use SOC produce better outcomes than those that do not (Noar et al., 2007). Nearly every study examined by Noar et al. (2007) demonstrated that those using tailored messages with theoretical concepts produced larger effect sizes than those that did not use theoretical concepts.

\section{Distance Learning in Physical Activity Promotion}

In the past decade, there has been a dramatic increase in the number of online resources for physical activity and physical education. As a result, the National Association for Sport and Physical Education (NASPE) released a position paper on guidelines for online physical education. NASPE defines online education in terms of student learning that is achieved via a web-based format (or through the Internet). Online education is accomplished by allowing students to submit course material to the teacher, use email technology, and by linking to online resources (NASPE, 2007). According to NASPE, "The curriculum should be research-based, follow best-practices guidelines, and aligned with national, state, and local standards" (p. 6).

Although online education is becoming more commonplace, there have been very few programs using research-based, tailored approaches to online physical activity or online physical education. In an article in the American Alliance for Health, Physical Education, Recreation and Dance's Update Plus, a number of online physical activity resources were described (Strecker, 2008). These resources included those created by organizations (such as the American Heart Association and Mayo Clinic), and through national initiatives.

The U.S. Department of Health and Human Resources, for example, provides an online resource called "SmallStep," which includes a "tracker" for logging physical 
activity time, goal setting, and tracking progress toward goals. The U.S. Department of Agriculture created the "My Pyramid Tracker," which is an online assessment tool for physical activity. Additionally, the President's Council on Physical Fitness has developed the Active Lifestyle program, which (unlike traditional school-based fitness testing) is geared toward those who are interested in tracking physical activity and progress. This program also affords participants the option of joining a peer group for social support. Similarly, America on the Move offers personalized community support, and free, online resources. However, it is not apparent that these types of online resources are based on theoretical models or constructs such as the Transtheorectical Model or SOC, which may produce limitations for behavior change interventions (Noar et al., 2007).

A number of innovative, theory-based online interventions have been created for non-traditional delivery of physical activity programming. For example, Pinto et al. (2002) described a novel computer-based and telephone counseling intervention based on the Transtheoretical Model and SOC that resulted in participants increasing moderate and vigorous amounts of physical activity.

A similar computer-based intervention using a tailored approach to stage of readiness to change was conducted with 771 participants. This study engaged its participants over the span of 6 months. Researchers examined whether participants were meeting the recommendations for physical activity. Those participants who were in the physical activity intervention groups significantly increased their levels of moderate and vigorous physical activity compared to those who did not receive the intervention (Vandelanotte, Bourdeaudhuij, Sallis, Spittaels, \& Brug, 2005). Spittaels, 
Bourdeaudhuij, and Vandelanotte (2007) also conducted an evaluation of a websitedelivered computer-tailored intervention on physical activity. The intervention produced significant increases in participants' active transport and leisure-time physical activity, and decreases in the amount of time participants spent sitting on weekdays.

A meta-analysis of 28 studies using media-based physical activity programs revealed that interventions using print and/or telephone methods resulted in changing physical activity in the short term. Additionally, those studies with more contacts and those with messages tailored to the target audience were most effective (Marcus, Owen, Forsyth, Cavill, \& Fridinger, 1998). When implementing a non-traditional physical activity program, particularly one based upon providing tailored messages, providers must consider participants' literacy, type of interface used, self-efficacy, risk perception, and attitude (Marcus, Nigg, Riebe, \& Forsyth, 2000).

\section{Active Living Every Day}

ALED is the Cooper Institute's "cornerstone course," and it is based on the Transtheoretical Model and SOC. The course focuses on getting sedentary people to be active and to maintain physical activity throughout their lives. Its purpose is to assist participants with finding ways to incorporate physical activity throughout their daily lives (Cooper Institute, n.d.). This course may be delivered by a provider, or may be completed as a self-study course. As part of the self-study option, participants may purchase a book and/or utilize the online support called ALED Online provided by the Cooper Institute and facilitated by Human Kinetics. The efficacy of the traditional 20week course has been documented (Dunn et al., 1998; Wilcox et al., 2006), but the efficacy of the 14- 
week online intervention has only been documented in one other study to date (Carr et al., 2008).

Initially, ALED was developed by Cooper Institute as "Project Active." Project Active was conducted from 1993-1997. This intervention was a randomized clinical trial with 235 sedentary participants. Participants were assigned to either a structured exercise group or a lifestyle group. Both groups received a 6-month intensive program with 18 months of "maintenance" intervention. Both groups had significant improvements in physical activity, body fat and cardiovascular health at 24 months. The researchers found that men increased overall physical activity and vigorous physical activity, but they conceded that these results were not statistically significant $(p=.59$, and $p=.11$, respectively) (Dunn et al., 1999). However, both groups also showed statistically significant reductions in total cholesterol and total cholesterol/HDL-C ratio (Dunn et al., 1997).

As a follow-up to that initial article, Sevick et al. (2000) reported that the costs of maintaining the lifestyle group at 6 months was just $\$ 46.53$, whereas the cost of the structured exercise group at 6 months was $\$ 190.24$ per participant per month. At 24 months, the costs for the lifestyle group were $\$ 17.15$, whereas the structured exercise group costs were and $\$ 49.31$ per participant per month.

From those initial studies, the Cooper Institute developed ALED. The Cooper Institute formed a partnership with Human Kinetics called Active Living Partners. This partnership is responsible for dissemination of both ALED and Healthy Eating Every Day. ALED was developed as a 20 -week program. However, universities were calling 
for a shorter program that would fit into a typical semester. Active Living Partners responded by condensing the 20 -week program into a 14 -week program.

Until the study by Carr et al. (2008) at the University of Wyoming, no other study had examined whether the ALED 14-week program was efficacious, or whether the 14week program delivered online was successful. The authors refer to a 16-week program rather than a 14-week program because they included pre- and post- testing time into the title. The purpose of their study was to determine whether ALED Online produced physical activity behavior change and improved cardio-metabolic disease risk factors in sedentary overweight adults.

The authors used a delayed intent-to-treat control condition. They had 14 participants enrolled in the intervention group, and 18 participants enrolled in the delayed intent-to-treat. Pedometers were used to measure step count at baseline, and cardiovascular disease risk factors (including age, total cholesterol, and HDL) were assessed. Findings of this study were that both groups increased average daily step count, but the intervention group increased step count by 1384 steps per day, whereas the control group recorded an additional 816 steps per day. The effect size for the intervention group on step count was large (.95).

Carr et al. (2008) examined participants' online journal activities. These activities include monitoring sedentary behaviors and identifying barriers. The researchers used the ALED Facilitators' interface to look at the number of log-in days by their participants, and the completion rates of the journal activities by their participants.

Although this first research project about ALED Online produced important findings, the authors noted that their research had some limitations. For example, the 
number of participants who were retained in the research project resulted in small sample sizes. Their attrition rate in one study was $23 \%$, and $51 \%$ in the second. Additionally, participants logged-in only every $11^{\text {th }}$ day of the intervention (as opposed to weekly), and completed an average of just 13 of 44 journal entries. The favorable finding, however, was that the $30 \%$ compliance in completing online journal entries was enough to produce changes in dependent variables.

\section{Summary of the Review of Literature}

Physical inactivity is related to poor cardiovascular health outcomes. The cost of physical inactivity is high in terms of treating medical conditions and from the risk of death from cardiovascular risk factors. For example, physical inactivity is related to obesity, increases in LDL cholesterol, and increases in BMI. Fortunately, it is apparent that physical activity is an important protective factor for preventing coronary heart disease (Sallis \& Owen, 1999).

People who adopt behavior change strategies often increase physical activity and improve coronary artery disease risk factors, including HDL, decreasing triglycerides, and reducing total body fat (The American College of Sports Medicine, 2000). The role of developing behavior change strategies such as self-monitoring, goal setting, and coping skills are instrumental in producing increases in physical activity and selfefficacy.

Programs using a theory-based tailored approach based on the Transtheoretical Model and SOC produce favorable outcomes. A British study with approximately 400 undergraduate students, found a high, positive relationships between SOC and physical activity (Daley \& Duda, 2007), while a South Korean study showed that Transtheoretical 
Model constructs such as behavioral processes, self-efficacy, and cognitive processes were significantly correlated with the stages of exercise behavior (Kim, 2006).

People who adopt behavior change strategies often increase physical activity and reduce coronary artery disease risk factors, including increasing HDL cholesterol, decreasing triglycerides, and reducing total body fat (The American College of Sports Medicine, 2000). The development of behavior change strategies such as selfmonitoring, goal setting, and coping skills are instrumental in producing increases in physical activity and self-efficacy.

Although there are many online resources for physical activity promotion, there are still few online interventions that use the Transtheoretical Model or SOC. In those online interventions that do use the Transtheoretical Model or SOC, levels of moderate and vigorous physical activity may be improved (Vandelanotte et al., 2005). Additionally, there may be significant increases in participants' active transport and leisure-time physical activity, with decreases in the amount of time participants spend sitting on weekdays (Spittaels, Bourdeaudhuij, \& Vandelanotte, 2007).

Distance learning is a promising approach to physical activity promotion. Although ALED was conceived as a 20-week, classroom-based program, the program has been adapted. Now, the program can be delivered in a 20 -week or 14 -week format, and may be delivered in the classroom, or in a self-paced manner with online support from Active Living Partners. Because there has been only one other study that examined the efficacy of ALED Online, more research in this area is warranted. 


\section{Research Hypotheses}

A review of the literature on ALED led to the following research hypotheses for this study.

\section{Physical Activity}

1) Participants enrolled in ALED Online will increase their levels of physical activity (as measured by step count) from Week 1 to Week 14.

2) Participants will retain intervention effects, and their step count totals will not fall below their pre-intervention step count numbers when measured at Week 21 ( 7 weeks past the intervention).

\section{Physiological Measures}

1) Participants will see improvements in HDL Weeks 7 and 14 in the intervention.

2) Participants will see reductions in LDL at Week 7 and Week 14 in the intervention.

3) Participants will see reductions in BMI at Week 7 and Week 14 in the intervention.

4) Participants will retain some intervention effects at Week 21. HDL and LDL cholesterol, and BMI will not worsen beyond their levels at Week 14. 


\section{CHAPTER 3}

\section{METHOD}

The purpose of this study was to examine the effects of a 14-week intervention based on Active Living Every Day (ALED) Online. ALED Online is a program developed by the Cooper Institute and managed by Human Kinetics through a partnership called Active Living Partners. ALED may be delivered in a traditional classroom setting, or may be delivered online. The program may be offered in a 20 -week format, or a 14week format. For this study, ALED Online was offered in the 14-week format. Outcomes of the online program and the process of delivering the program were analyzed. Outcome considerations included: whether ALED Online increased physical activity among participants (as measured through step counts), whether physiological changes (cholesterol and body mass index) were apparent throughout the intervention, and whether participants in ALED Online progressed or regressed through the Stages of Change (SOC). Process measures included examining the nature of retention of participants in the study and the quality of participants' responses to the "Life Assignments" homework component of ALED Online. This chapter includes sections describing the participants, research design, pilot research, instrumentation, procedure, and data analysis.

\section{Participants}

This study included 21 participants, with each participant serving as his/her own control. Convenience sampling was used to recruit participants. Participants were recruited through community-based organizations (such as family resource networks and senior citizens centers), employee wellness programs, media outlets (including 
newspaper, regional television news), and West Virginia University units (such as the College of Physical Activity and Sports Sciences and Student Recreation). Material used for recruitment included standard prepared resources from Active Living Partners. This promotional material included fliers, press releases, posters, public service announcements, and newspaper and radio advertisement copy.

Institutional Review Board for the Protection of Human Subjects approval was obtained prior to the intervention. Participants were asked to adhere to research protocol approved by the Institutional Review Board, and outlined in the letter of consent they signed prior to the start of the intervention. Participant selection criteria included the ability to:

1. Participate in four health screenings throughout the intervention

2. Read at least at an eighth grade reading level

3. Have access to the internet at least one hour per week

4. Be willing to be contacted by email and phone for an interview

5. Have the ability to complete each weekly learning module in order and on-time.

Participants in this study who were previously sedentary were not excluded from the study. As part of the established protocol in ALED, each potential participant was required to submit a Physical Activity Readiness Questionnaire (PAR-Q) (Canadian Society for Exercise Physiology, 1994), indicating his/her ability or inability to participate in physical activity. If a participant answered "Yes" to any question on the form, he/she was advised to contact his/her physician. If the physician cleared the participant for moderate intensity physical activity, the participant was permitted to enroll 
in the study. Additionally, participants must have been able to ambulate independently, and (after instruction) must have had the ability to wear a pedometer correctly. Potential participants had the right to refuse to complete portions of the study.

Some potential participants were excluded from the study. Pregnant women were excluded, as well as people under the age of 18 or over the age of 69. (The PAR-Q is appropriate for use with non-pregnant individuals ages 15-69). Additionally, potential participants were excluded if they indicated an inability to comply with the research protocol.

\section{Research Design}

This study used a mixed method, quantitative/qualitative research design framework. A multivariate, single group repeated measures design, with one withinsubjects independent variable was used to examine outcome measures (or dependent variables). The independent, within-subjects variable was Time of Assessment $\left(\mathrm{O}_{1}, \mathrm{O}_{2}\right.$, $\mathrm{O}_{3}$, and $\left.\mathrm{O}_{4}\right)($ See Figure 1). Five dependent variables were measured on four occasions including (a) high-density lipoprotein cholesterol (HDL), (b) low-density lipoprotein cholesterol (LDL), (c) Body Mass Index (BMI), (d) Stage of Change (SOC), and (e) physical activity estimates (step counts).

Qualitative methodology included using a sequential explanatory approach (Cresswell, 2003) to examine process measures. A sequential approach is often used to "...ground quantitative research through the use of formative qualitative approaches" (National Institutes of Health, 2009). An examination of the participants' Life Assignments was used to determine adherence to the program. 
The interview data were triangulated with document analysis. Two types of documents from ALED were examined. Participants' Life Assignments were examined to determine the number of assignments completed and the nature of the statements in those assignments. Second, the Stages of Readiness to Change assignments (Blair et al., 2001) were examined to determine whether participants' SOC was related to the qualitative nature of their statements in the interviews and Life Assignments.

\section{Pilot Research}

Pilot research was completed from May-June 2008. The purpose of the pilot research was to test the suitability of the instruments used in the study. Four adults ranging in age from 33-50 years were recruited as part of a class project in the Spring, 2008 semester. The adults recruited for the pilot research were asked to complete at least two weekly ALED modules (including Life Assignments and Stage of Change Decision Tree), wear a pedometer for three days, and complete a demographic information worksheet (see Appendix C). Participants in the pilot research were asked to provide their feedback regarding the suitability, ease of use, and comfort level with using each of the instruments. The researcher gained experience in delivering the program online, distributing material, and determining how user-friendly the program may be perceived by participants.

Lipid panel blood analyses were not pilot tested. The researcher has coordinated community-based multiphasic blood screenings for approximately 6,000 patients, and worked cooperatively with Laboratory Corporation of America during data collection. 


\section{Instrumentation}

Instrumentation for the quantitative measures of the dependent variables are divided by type. Description of physical activity instruments, physiological instruments, and ALED’s process instruments for this proposed study are provided.

\section{Physical Activity Instruments}

Physical Activity Readiness Questionnaire (PAR-Q). The PAR-Q (see Appendix A) was originally developed by British Columbia Ministry of Health, and revised by an Expert Advisory Committed convened by the Canadian Society for Exercise Physiology (1994). The PAR-Q is a risk assessment tool used by individuals who plan to increase their physical activity. It is a questionnaire used primarily for people ages 15-69. The PAR-Q is the instrument endorsed by Active Living Partners as a screening tool prior to participation in ALED. The questionnaire asks respondents to indicate whether they have been told by a doctor that they have a heart condition, whether they have experienced pain in the chest with physical activity, chest pain without physical activity, a loss of balance due to dizziness or unconsciousness, bone or joint problems, prescription drug use for blood pressure or heart condition, or any other condition that might have precluded them from increasing physical activity.

If a participant answers "yes" to any one of the questions on the PAR-Q, he/she is advised to talk to his/her doctor before becoming physically active. For this study, any participant who answered "yes" to a question on the PAR-Q was referred to a primary care physician. These participants were allowed to participate in the study if they provided the researcher with a release statement from their physician. This protocol is consistent with ALED's pre-participation screening. 
Pedometers. The purpose of using pedometers for this study was to approximate the amount of physical activity participants were acquiring by measuring their step counts. A number of studies have found pedometers are reliable for physical activity research (Bassett et al., 1996; Tryon, Pinto, \& Morrison, 1991). Bassett et al. (1996) found that inter-device reliability was high when subjects wore the same brand of pedometer on both their left and right side of the body, and Tryon et al. (1991) found an approximate $5 \%$ error when testing pedometers in laboratory conditions.

For the purposes of this study, step counts were measured through the use of a Yamax Digi-Walker NL-800 pedometer over seven days on four occasions. Adding each participant's daily step count and dividing by the number of days recorded yielded a mean step count per day. This served as the dependent variable for physical activity for each participant on each testing occasion. Tudor-Locke and Bassett (2004) have suggested indices for classifying physical activity by step count. They suggest $<5,000$ steps per day is sedentary, 5,000-7,499 is low active, 7,500-9,999 is somewhat active, $>$ 10,000 steps is active, and $>12,500$ is highly active.

Reliability and validity of Digi-Walker pedometers have been established through a number of studies (Cyarto, Myers \& Tudor-Locke, 2004; LeMasurier, Lee, \& TudorLocke, 2004; Schneider, Crouter, \& Bassett, 2004). LeMasurier et al. (2004) and Schneider et al. (2004) found that various Digi-Walkers were accurate for assessing step counts among adults. The Digi-Walker NL-800 was chosen for this study because it stores seven days of step counts into its memory.

Tudor-Locke et al. (2005) found that “... a minimum of three days of pedometer data is sufficient to estimate free-living adult pedometer-determined activity in a week." 
However, for this study, participants were asked to log seven days of step counts during Weeks $0,7,14$, and 21 . Using seven days helped to ensure that there are at least three usable days of pedometer readings in the event that participants failed to record their step counts. In the event that some days' step counts seemed (to the participant) to be inaccurate, participants were asked to use a step count log to document any discrepancies in their pedometers' readings.

Stage of Readiness to Change Decision Tree. Assessing a participant's SOC is an important consideration for implementing ALED. ALED was based on the SOC construct of the Transtheoretical Model developed by James Prochaska (1994). Miilunpalo et al. (2000) found that "...the behavior of interest must be specified before stages of change in a population can be obtained" (p. 435). For the purposes of this study, the behavior of interest is physical activity. On four testing occasions, participants were asked to complete an assignment which guided them through the process of identifying which SOC they were in with regard to current levels of physical activity (see Appendix B). Participants followed the decision tree by asking themselves the following questions:

1. “Are you accumulating at least 30 minutes of moderate-intensity physical activity on most (five or more) days of the week?"

2. “Are you accumulating at least 30 minutes of moderate-intensity physical activity at least one day per week?"

3. "Do you intend to increase your physical activity?"

4. "Have you been doing this on a regular basis for the last six months?" 
The answers to these questions will lead participants to identify their current stage of readiness to change (Blair et al., 2001).

\section{Physiological Instruments}

Lipid panel blood analysis. Fasting lipid panel blood analysis was completed with participants at Laboratory Corporation of America (LabCorp) locations in North Central West Virginia, and each blood sample was analyzed at LabCorp's Fairmont, West Virginia laboratory. Venous blood was collected according to standard phlebotomy techniques with venostasis following an overnight (8-12 hour) fast. Fasting serum lipid/lipoprotein (HDL and LDL) was determined by LabCorp's clinicians.

Body mass index. BMI was determined by the researcher. Participants were weighed and had their height measured (without shoes) on four occasions throughout the study. Body mass index was calculated by using weight in kilograms divided by height in meters squared (BMI; $\left.\mathrm{kg} / \mathrm{m}^{2}\right)$.

Process Instruments

Life Assignments tracking. Participants completed Life Assignments, and emailed weekly assignments as attachments to the researcher. Using the Facilitator's Tools through Active Living Partners, the researcher entered the number of completed assignments for each participant. Compliance with the program is typically defined as completing $80 \%$ of Life Assignments (ALED Facilitator Training, 2008). However, for the purposes of this study, when a participant notified the researcher that he/she was withdrawing from the study, he/she was considered a drop-out. High-achievers were identified by examining which participants completed at least 19 of 20 weeks worth of assignments (over the 14-week timeframe). Mid-achievers were those participants who 
completed the median number of assignments (excluding drop-outs). Once drop-outs, mid-achievers, and high-achievers were identified, their Life Assignments were examined in order to identify potential themes regarding their stage of readiness to change, attitude toward physical activity, or perceptions about the program. Open coding was used to generate potential themes. The themes gleaned from examination of the Life Assignments were triangulated with data collected through semi-structured interviews.

Semi-structured interviews. Purposeful sampling using the number of completed Life Assignments as the selection criteria was used to identify three drop-outs, two midachievers, and three high-achievers. Semi-structured interviews were conducted after each identified interviewee finished their participation in the program (see Appendix D).

Drop-outs, mid-achievers, and high-achievers were contacted by the researcher for semi-structured interviews. Participants could choose to respond to the interview questions via email, by phone, or in person. None chose to be interviewed via email, and each interviewee was interviewed by phone or in person. Interview questions focused on the ease of using the online format, stage of readiness to change, and barriers to participation.

The interviews lasted 20-30 minutes in duration. The interviews were transcribed within an hour of each interview, and were sent to each interviewee for member checks. Open coding was used to determine if there were any themes surrounding participants' perceptions of the ALED Online program or physical activity. 
Procedure

The procedures for this study occurred in seven distinct time frames: Researcher Training, Role of the Facilitator, Institutional Review Board Approval, Recruitment, Weeks 1-7, Weeks 7-14, and Weeks 14-21. Each time frame will be described. Researcher Training

ALED Director and Facilitator Training. The researcher for this study was trained by Active Living Partners as an ALED Director and Facilitator. Nine ALED homework assignments and six general facilitation assignments were completed by the researcher. These assignments provided a background for the theoretical basis for the development of the program (Transtheoretical Model and SOC), physical activity guidelines, and facilitation techniques. Additionally, completion of online modules was required. These modules included demonstrations of ALED sessions, profiles of typical ALED participants, and mock participant interviews. These modules also explained procedures for delivering the program. Training commenced with a two-day, web-based workshop facilitated by an Active Living Partners program manager. After the webbased workshop, facilitators are required to take a Facilitator Exam online, and pass with an $80 \%$ score. The researcher for this study passed with a score of $95 \%$.

Role of the Facilitator. Prior to the implementation of the study, the facilitator's role was operationalized. Active Living Partners suggested referring to the University of Wyoming study (Carr et al., 2008) and to the methods used by the U.S. Coast Guard. Carr et al. (2008) described how their research team interacted with participants. Carr et al. used weekly email/phone contact for the first two weeks, then email contact every other week. Additionally, Active Living Partners suggested modeling the ALED online 
delivery after the U.S. Coast Guard's implementation of Active Living Partner's Healthy Eating Every Day Program. The U.S. Coast Guard's facilitator limits her communication to two weekly emails. One email communicates the objectives for the week, and the second weekly email summarizes that week's information and provides a preview for the following week (Ross, 2008).

For the purpose of this study, contact was limited to two weekly emails sent to the group, at large. Participants received two weekly emails which instructed them to complete Life Assignments. On Sunday of each week, participants received an introduction to that week's activities. The Sunday emails included instructions for completing tasks, the key concepts for each module, the learning objectives, a "CheckIn" section to inquire about their progress, and a homework assignment. On Friday of each week, participants received a review of the week's key concepts, reminders to submit Life Assignments (if they hadn't done so already), and a preview of the upcoming week's topics. Questions elicited by participants about the Life Assignments or the research project received simple and limited responses via email from the facilitator.

Qualitative methods. As part of the researcher's plan of study in West Virginia University's doctoral program in Kinesiology, she has taken two qualitative research methods courses. The first qualitative methods course allowed the researcher to gain experience in interviewing and document analysis. The second course allowed the researcher to develop the qualitative component for this chapter and to pilot test the intervention. 
Pilot testing. Pilot testing occurred with 4 participants in Spring, 2008. Pilot testing gave the researcher insight into participants' perceptions of ALED Online and the suitability of the instrumentation used in the study.

\section{IRB Approval}

Institutional Review Board approval for the Protection of Human Subjects was obtained prior to recruitment for the study. The protocol for "The Effects of Active Living Every Day’s Online Self-Study Option on Physical Activity” was marked "approved."

\section{Recruitment}

Participants for the study were recruited through community-based organizations (such as family resource networks and senior citizens centers), employee wellness programs, West Virginia University media outlets (such as radio, newspaper, and regional television news), and West Virginia University units (such as the College of Physical Activity and Sport Sciences and Student Recreation). Material used for recruitment included fliers, press releases, posters, public service announcements, and newspaper and radio advertisement copy. Each flier, press release, poster, public service announcement, and advertisement copy included the researcher's phone number, address, and email. Potential participants were encouraged to contact the researcher for information. When a potential participant indicated an interest in joining the research study, a packet of information was mailed.

Material sent to the potential participant included: a registration form, an overview of the program, a SOC decision tree, and a PAR-Q. A letter of consent was approved by the Institutional Review Board in the protocol submitted by the researcher 
and was distributed to each participant during the first on-campus meeting. Participants were informed that they could withdraw consent at any time. Second, participants received an overview of the program that outlined topics covered in the program and expectations for participants. This letter explained that the participant may be chosen to be included in the study or excluded from the study. Third, a SOC decision tree worksheet was sent to potential participants. Participants were asked to follow the decision tree and circle the stage they were in. This worksheet was returned to the researcher during the first screening. Finally, participants returned a registration form including demographic information (names, addresses, phone numbers, email addresses, gender, race, height, and weight).

Prior to beginning the program, the participants met with the researcher on campus on the Saturday before Week 1. Participants received a packet including a Yamax NL-800 pedometer and ALED book with online access. They received information about how to use the pedometer and how to use their unique ALED key code to establish their profile in the researcher's "class" on the Active Living website.

Participants were asked to wear the pedometer for seven days, log their daily step counts on their pencil and paper log, and return the pedometer to the researcher in the padded reply envelope provided at the end of the week.

During this on-campus meeting, the participants were measured (weight and height without shoes), received instruction on using the pedometer, completed the SOC decision tree, and shown the ALED website. Additionally, participants were given a LabCorp order form, which they took with them to a LabCorp office for lipid blood 
screening. Participants were sent an email reminder to have their blood drawn and complete one week of wearing the Yamax pedometer prior to beginning the program. Weeks 1-7

During Weeks 1-7, participants were instructed to log onto ALED Online. They were asked to complete the following modules: Getting Started (Week 1), Ready, Set, Go (Week 2), Making Plans and Barriers and Benefits (Week 3), Over, Under and Through (Week 4), Let's Burn Some Calories (Week 5), Setting Goals and Rewarding Yourself (Week 6), and Enlisting Support and Gaining Confidence (Week 7). They were asked to complete the forms associated with each module, and send those forms to the researcher as an email attachment. Prior to Week 7, the researcher mailed a Yamax NL-800 pedometer to each participant, and asked participants to wear the pedometer again for seven days prior to our Week 7 on campus meeting.

Weeks 7-14

At Week 7, participants returned to campus for the second screening. This screening included the same measures as the first screening (SOC decision tree, height, and weight). Additionally, participants were asked to bring their pedometers and step count log with them to campus so that the step count recorded by the participant could be verified by examining the pedometer's memory. Participants received a lab order form for lipid blood analysis, and were asked to have their blood work completed during Week 7.

At Week 7, the group continued the second half of the intervention. They completed the following online modules: Strengthening the Foundation (Week 8), Avoiding Pitfalls (Week 9), Defusing Stress (Week 10), Step by Step and Managing 
Time (Week 11), Exploring New Activities (Week 12), Becoming a Hunter-Gatherer and Positive Planning (Week 13), and Making Lasting Changes, and Onward and Upward (Week 14). Prior to Week 14, pedometers and step count logs were mailed to participants, and they were asked to record their step count for the seven days prior to our Week 14 meeting on campus.

Weeks 14-21

Participants from the group concluded their online sessions on Week 14. During Week 14, participants returned to campus for their third screening. This screening was identical to screenings one and two described above.

At Week 14, three drop-outs, two mid-achievers, and three high-achievers from the group were identified. The researcher contacted each participant by email to see if they were willing to participate in an interview. Interview questions centered around their reasons for dropping-out or complying with the program. Additionally, the interviewees' Life Assignments and SOC decision trees were examined to determine whether any themes emerged.

On Week 21, the group returned to campus for their final screening. This screening was identical to those described in screenings 1-3 described above, with the addition of a Control Condition Questionnaire (see Appendix E). Participants were asked to describe whether their physical activity or eating habits had changed within the past seven weeks (during the control condition). At the completion of the program, the researcher mailed a pedometer to each participant for his/her own use. 


\section{Data Analyses}

Because this study employed quantitative measures of dependent variables and a qualitative approach to examining the program, quantitative and qualitative data analyses were necessary. SPSS Version 17 was used for quantitative statistical analysis. Multiple data sources (including interview transcripts and document analysis) were used to triangulate qualitative data.

In order to assess the impact of ALED Online, descriptive statistics were generated at four points during the study $\left(\mathrm{O}_{1}, \mathrm{O}_{2}, \mathrm{O}_{3}\right.$, and $\left.\mathrm{O}_{4}\right)$ relating to the dependent variables of (a) physical activity (measured through step count), (b) HDL, (c) LDL, (d) BMI, and (e) current SOC. Means and standard deviations were calculated for each testing occasion.

A repeated-measures multivariate analysis of variance (MANOVA) was performed using the following dependent variables: step count, HDL, LDL, SOC, and BMI for the first three testing occasions (independent variables). Because of participant mortality, the purpose of this first analysis was to determine whether there were changes that occurred across the first three testing occasions for the entire group.

Because there was a small sample size for $\mathrm{O}_{4}$, MANOVA with follow-up ANOVAs were performed to see whether there was a significant effect on each of the dependent variables for only those participants who completed all four testing occasions (research adherents). To determine where changes in the dependent variables occurred with respect to the testing occasions, the Tukey LSD post hoc (with no correction for Type I error) was performed for descriptive purposes. Although it is not generally 
recommended, "When sphericity is definitely not violated, Tukey's test can be used," (Field, 2005, p. 442).

Because data analyzed in a quantitative manner cannot explain perceptions of participants in the intervention, a sequential explanatory approach was used. According to Patton (2002), "A rich variety of methodological combinations can be employed to illuminate an inquiry question" (p. 248). Further, Patton contends, "Studies that use only one method are more vulnerable to errors linked to that particular method" (p. 248).

Procedures for coding qualitative data were identified by Strauss and Corbin (1990), and were based upon the original concepts of grounded theory (Glaser \& Strauss, 1967). Data analysis for this study included selective coding and the generation of categories or themes. Categories or themes were based upon data collected through interviews, observations, and notes or memos created by the researcher (Creswell, 2005).

For the purposes of this dissertation, documents and interviews served as data sources. Tracking of the Life Assignments was done using the Facilitator's interface on the ALED website, and through multiple rounds of qualitative data analyses of the participants' interviews. The interviews and assignments were reviewed in order to generate potential codes or themes.

Once interviews were transcribed, document analysis began. Statements made by the participants during the interviews were recorded by note-taking. Notes were "cooked" (or refined), then transcribed. The transcribed data were examined using open coding procedures to determine whether themes emerged that related to physical 
activity, SOC, or the online program's ease of use. These data were triangulated by examining the type of statements written in the Life Assignments. These methods are consistent with those described by Patton (2002). If spoken statements were similar in nature to the written statements of participants, themes surrounding physical activity, SOC, or the ease of using the online program could be verified. The use of multiple data sources and multiple research methods provided a more rich description of this study. 


\section{CHAPTER 4}

\section{RESULTS}

The purpose of this study was to examine the effects of a 14-week intervention based on Active Living Every Day (ALED) Online. Outcomes of the 14-week online program and the process of delivering the program were analyzed. Outcome considerations included: whether ALED Online increased physical activity among participants (as measured through step counts), whether physiological changes (cholesterol and body mass index) were apparent throughout the intervention, and whether participants in ALED Online progressed or regressed through the Stages of Change (SOC). Process measures included examining the nature of retention of participants in ALED Online, and the quality of participants' responses to the Life Assignments homework component of ALED Online. This chapter includes sections describing analyses of descriptive statistics, quantitative analyses, qualitative analyses, and integrated analyses of the mixed methodology.

Analyses of Descriptive Statistics

SPSS Version 17 and the ALED Facilitator's Interface were used for quantitative descriptive statistical analyses. Descriptive statistics are provided to describe the Study Population and Completion of ALED Life Assignments.

\section{Study Sample}

Twenty-one participants consented to take part in the ALED Online Research Project at West Virginia University. There were 16 women and 5 men who participated in the study. These participants resided in four counties in North Central West Virginia and one county in Southwest Pennsylvania. The mean age of participants was 48.95 
$(\mathrm{SD} \pm$ 9.346). Participants had the option to identify their race/ethnicity without being restricted to pre-set racial or ethnic categories (see Appendix C). Eighteen participants identified themselves as "white" or "Caucasian," one identified herself as "Mixed," and two identified themselves as "Hispanic" or "Spanish."

Completion of ALED Life Assignments

Participants were asked to complete 20 weeks (or modules) of Life Assignments in the 14-week intervention. The order of these assignments was prescribed by Active Living Partners and communicated to the participants via email. Based on assignment completion, high-achievers were those who completed all 20 modules, mid-achievers were those who completed 10-11 modules, and drop-outs were those who completed 3-5 modules. The average Life Assignment completion rate was 7.29 modules per person (including drop-outs).

The group (including drop-outs) was logged onto the website for a total of 56.63 hours. The average time spent online throughout the entire intervention was 2.7 hours per participant (including drop-outs). Participants spent the greatest amount of time on the Life Assignment titled "My Personal Time Study." Additionally, participants spent the majority of their time focusing on the "My Benefits of Physical Activity" and "My Personal Successes (Habits I've Changed for the Better)" Life Assignments.

Quantitative Analyses

Inferential statistics were generated by SPSS version 17 and are provided to describe changes in physical activity, physiological changes (including BMI, highdensity lipoprotein (HDL) and low-density lipoprotein (LDL) cholesterol), and SOC. 
Participant attrition throughout the study was a concern. Of the 21 participants who started the program, just 8 participants completed testing for each of the dependent variables on all four testing occasions. There were a seemingly robust number of participants at $\mathrm{O}_{3}$, so a repeated measures multivariate analysis of variance (MANOVA) was performed for testing occasions $\mathrm{O}_{1}, \mathrm{O}_{2}$, and $\mathrm{O}_{3}$ on 13 participants for whom there were complete data. Mauchly's Test of Sphericity for average steps indicated that sphericity was not violated $\left(\mathrm{X}^{2}(2)=.085, \mathrm{p}=.958\right)$. However, examining the Hotelling's Trace statistic revealed no overall statistically significant intervention effects for the group of 13 participants from $\mathrm{O}_{1}$ to $\mathrm{O}_{3}[\mathrm{~F}(10,3)=.626, \mathrm{p}=.749$, n.s. $]$.

To determine whether there were statistically significant differences from $\mathrm{O}_{1}$ through $\mathrm{O}_{4}$ (the control condition) for those 8 participants who completed all testing occasions (e.g. "research adherents"), an omnibus repeated measures MANOVA was performed with all dependent variables (steps, BMI, HDL, LDL, and SOC) by time for $\mathrm{O}_{1}, \mathrm{O}_{2}, \mathrm{O}_{3}$, and $\mathrm{O}_{4}$. Using Hotelling's Trace, there were overall statistically significant intervention effects for those who completed the intervention $[F(1,5)=2.26, p=.021]$, with a large observed power (.922). Follow-up within-subjects, repeated measures ANOVAs were performed for each dependent variable.

\section{Physical Activity}

Physical activity was approximated with step counts. Participants were asked to wear a Yamax NL-800 pedometer for seven consecutive days at four times throughout the study. On testing $\mathrm{O}_{1}$, all 21 participants recorded step count data, but compliance with wearing the pedometer decreased on each subsequent occasion (see Figure 2). On $\mathrm{O}_{2}, 16$ participants recorded step count data. On $\mathrm{O}_{3}, 15$ participants recorded step count 
data. On $\mathrm{O}_{4}$ (the control condition), just 13 participants recorded step count data. The mean average daily step counts for each occasion were $7225.29(\mathrm{SD} \pm 1499.05), 7806.57$ $(\mathrm{SD} \pm$ 1743.33), $6924.29(\mathrm{SD} \pm 1939.89)$, and $9345.29(\mathrm{SD} \pm$ 3076.03), respectively.

Mauchly's Test of Sphericity for average steps from $\mathrm{O}_{1}$ to $\mathrm{O}_{4}$ for research adherents indicated that sphericity was not violated $\left(X^{2}(5)=10.108, p=.078\right)$. Examining the within-subjects, repeated measures ANOVA revealed no statistically significant differences for average daily step count from $\mathrm{O}_{1}$ to $\mathrm{O}_{4}$ for research adherents $[\mathrm{F}(1,3)=$ $358.31, \mathrm{p}=.188]$.

\section{Physiological Changes}

The physiological changes of interest in this study included BMI and HDL and LDL cholesterol. Measures of height and weight (for BMI), and HDL and LDL cholesterol were taken at four points through the study $\left(\mathrm{O}_{1}, \mathrm{O}_{2}, \mathrm{O}_{3}\right.$, and $\left.\mathrm{O}_{4}\right)$.

BMI. BMI was calculated by using weight in kilograms divided by height in meters squared $\left(\mathrm{BMI} ; \mathrm{kg} / \mathrm{m}^{2}\right)$. For the research adherents, BMI remained relatively consistent over time. Average BMI's for $\mathrm{O}_{1}$ to $\mathrm{O}_{4}$ were $30.06(\mathrm{SD} \pm 3.84), 29.97(\mathrm{SD} \pm$ 3.65), 29.83 ( $\mathrm{SD} \pm 3.72$ ), and 29.29 ( $\mathrm{SD} \pm 3.29)$, respectively. Mauchly’s Test of Sphericity for $\mathrm{BMI}$ from $\mathrm{O}_{1}$ to $\mathrm{O}_{4}$ for research adherents indicated that sphericity was not violated $\left(X^{2}(5)=6.01, p=.315\right)$. Examining the within-subjects, repeated measures ANOVA revealed no statistically significant differences $B M I$ from $\mathrm{O}_{1}$ to $\mathrm{O}_{4}$ for research adherents $[\mathrm{F}(1,3)=2.237, \mathrm{p}=.108, \mathrm{n} . \mathrm{s}$.$] .$

HDL Cholesterol. Participants had fasting lipid profiles (including both HDL and LDL cholesterol) prepared by Laboratory Corporation of America (LabCorp) on four occasions. For HDL, LabCorp uses a reference interval of $>39 \mathrm{mg} / \mathrm{dL}$ for desirable HDL 
levels. In general, research adherents' HDL profiles improved over time (see Figure 3). Average HDLs for $\mathrm{O}_{1}$ to $\mathrm{O}_{4}$ were $58.43(\mathrm{SD} \pm 14.85), 61.86(\mathrm{SD} \pm 15.17), 65.86(\mathrm{SD} \pm$ 19.83), and 62.00 ( $\mathrm{SD} \pm 14.87)$, respectively. Mauchly's Test of Sphericity for HDL from $\mathrm{O}_{1}$ to $\mathrm{O}_{4}$ for research adherents indicated that sphericity was not violated $\left(\mathrm{X}^{2}\right.$ $(5)=3.52, p=.628)$. An examination of the within-subjects, repeated measures ANOVA revealed statistically significant intervention effects for $\mathrm{HDL}$ from $\mathrm{O}_{1}$ to $\mathrm{O}_{4}$ for research adherents $[\mathrm{F}(1,3)=3.99, \mathrm{p}=.024]$. The Tukey LSD post hoc (with no correction for Type I error) was performed for descriptive purposes. The Tukey LSD indicated statistically significant differences for $\mathrm{HDL}$ from $\mathrm{O}_{1}$ to $\mathrm{O}_{3}(\mathrm{p}=.019)$.

LDL Cholesterol. For LDL, LabCorp uses a reference interval of 0-99 mg/dL for desirable LDL levels. They suggest assessing a patient for risk factors if the initial LDL cholesterol result is $>100 \mathrm{mg} / \mathrm{dL}$. LDL profiles improved over time for research adherents (see Figure 4). Average LDLs for $\mathrm{O}_{1}$ to $\mathrm{O}_{4}$ were 129.00 ( $\left.\mathrm{SD} \pm 50.66\right), 107.86$ ( $\mathrm{SD} \pm$ 38.74), $97.14(\mathrm{SD} \pm 26.28), 92.71(\mathrm{SD} \pm 29.57)$, respectively. An examination of the within-subjects, repeated measures ANOVA revealed statistically significant intervention effects for $\mathrm{LDL}$ from $\mathrm{O}_{1}$ to $\mathrm{O}_{4}$ for research adherents $[\mathrm{F}(1,3)=4.05, \mathrm{p}=.023]$. The Tukey LSD indicated statistically significant differences for LDL from $\mathrm{O}_{1}$ to $\mathrm{O}_{4}$ $(\mathrm{p}=.041)$

\section{Stage of Readiness to Change}

SOC was assessed at multiple points throughout the intervention. The participants were asked to re-assess their SOC throughout the course of the intervention by completing the Readiness to Change form provided in the Life Assignments. For the purposes of data analyses, $\mathrm{SOC}$ was assessed during on-campus visits by time for $\mathrm{O}_{1}, \mathrm{O}_{2}$, 
$\mathrm{O}_{3}$, and $\mathrm{O}_{4}$. $\mathrm{SOC}$ was labeled with discrete numbers (pre-contemplation=1, contemplation $=2$, preparation $=3$, action $=4$, and maintenance $=5$ ).

Research adherents' SOC improved over time (see Figure 5). Average SOCs for $\mathrm{O}_{1}$ to $\mathrm{O}_{4}$ were 3.29 (preparation), 3.71 (preparation), 3.86 (preparation), 4.14 (action), respectively. Mauchly's Test of Sphericity for SOC from $\mathrm{O}_{1}$ to $\mathrm{O}_{4}$ for research adherents indicated that sphericity was not violated $\left(\mathrm{X}^{2}(5)=5.64, \mathrm{p}=.352\right)$. The within-subjects, repeated measures ANOVA indicated statistically significant intervention effects for SOC from $\mathrm{O}_{1}$ to $\mathrm{O}_{4}$ for research adherents $[\mathrm{F}(1,3)=3.52, \mathrm{p}=.036]$. The Tukey LSD indicated statistically significant differences for SOC from $\mathrm{O}_{1}$ to $\mathrm{O}_{3}(\mathrm{p}=.030)$ and from $\mathrm{O}_{1}$ to $\mathrm{O}_{4}(\mathrm{p}=.045)$. It should be noted that the average research adherents' $\mathrm{SOC}$ on $\mathrm{O}_{1}$ was preparation, whereas drop-outs' $\mathrm{SOC}$ at $\mathrm{O}_{1}$ ranged from contemplation to action.

Qualitative Analyses

From the group of 21 participants in the ALED Online research project, three subgroups emerged. These sub-groups included high-achievers, mid-achievers, and dropouts. The purpose of naming these sub-groups was to frame descriptions of participants' experiences and to provide a representative description of typical participant experiences.

For each of the three sub-groups, data were triangulated through interviews (see Appendix D) and document analysis. Interviewees were purposefully selected based on the number of Life Assignments completed. The three high-achievers selected completed all 20 Life Assignment modules. Two mid-achievers completed the median number of Life Assignment modules (10 and 11). One drop-out completed 3 Life Assignments, and two drop-outs completed 5 Life Assignment modules. 
After interviews were conducted with the three high-achievers, two midachievers, and three drop-outs, their interview data was triangulated with their Life Assignments entitled "My Personal Time Study," "My Benefits of Physical Activity," and "My Personal Successes (Habits I've Changed for the Better)." From the interview and document analysis, seven themes emerged. Themes included Rationalization, Ease of Use, Thoughts, Behaviors, Time, Facilitation, and Accountability. These themes are described below.

\section{Rationalization}

For the eight interviews conducted, the Rationalization theme garnered the highest number of unique statements (56). The Rationalization theme describes (1) how participants justified their persistence in ALED Online, or (2) reasons for dropping out of the ALED Online research project. Statements were typically positive for high-achievers and mid-achievers (e.g. "I want to be able to play ball with the kids"). A common positive rationalization for persisting with ALED Online and physical activity was weight control. The high-achievers mentioned specific reasons for "sticking with it" (including weight loss). The mid-achievers discussed the health benefits of physical activity (e.g. “muscle tone versus weight," "my skin looks healthier”). One participant wrote, "I've lost weight since starting this program." She also wrote, "I feel better and my hip has stopped hurting."

The drop-outs' rationale for dropping-out of ALED Online were typically negative (e.g. “...everyone else's needs are more important than my own”). Drop-outs often ascribed their failures to their own health issues or the health issues of others (e.g. 
rheumatoid arthritis, allergies, sick or deceased family members). In an interview, one drop-out said,

"I thought it was a good program, but I wanted something to help me figure out things I could do. My problems were rheumatoid arthritis (RA) and allergies. When my allergies are bothering me, I can't go outside. I had to quit.... It wasn't what I was looking for as far as what I could do. Years ago when I needed prodding, this would have helped. Now I need to find out what I can do now with RA. Before RA, I was walking every day, and once I got that under control, then allergies. I've got to figure out what I can do with my circumstances. Yesterday, for example, I swell when I have a reaction. I couldn't hardly stand up."

The Rationalization theme was supported through triangulation of Life Assignment data. Participants rationalized their lack of participation in physical activity by describing friends getting in the way, receiving a negative health diagnosis, and the outdoors (e.g. the effects of allergies, heat, or humidity).

Ease of Use

The Ease of Use theme garnered the second highest number of unique statements (46) in the interviews. Generally, interviewees thought the program was easy to use. Seven of eight interviewees preferred using the book to using the internet, although most felt the internet had very good resources. Many believed the online component was “informational and user-friendly," but many participants preferred using the book simply because they "liked sitting down to read." One interviewee remarked, "I liked the book! The chapters were short, and not difficult to read. There were real-life situations and it 
shared other people's struggles and how they overcame them. I thought that was real helpful."

There were some relatively minor issues with the online portion of the course that were discussed by the interviewees, but none of those issues seemed to affect the degree to which someone participated. These issues included their ability to enter the correct user names and passwords and saving Life Assignment forms. One high-achiever said, "How to save the forms and rename the shells was a challenge at first. If you explained it in an email, I didn't read it carefully." When asked about how difficult it was for one drop-out to save her Life Assignments and attach them to an email, she said, "It was a little frustrating, but not major."

\section{Thoughts}

The theme Thoughts garnered the third highest number of unique statements from all eight interviewees (32). This category is uniquely different than that Rationalization category. In the semi-structured interview (see Appendix D), interviewees were asked specifically, "Did you feel that this program changed your behaviors or thoughts about physical activity?"

When asked this question, drop-outs had few or non-specific thoughts about physical activity. When asked if the program changed her thoughts about physical activity, one drop-out said, “...it probably would have if I stuck with it.” When prodded, she remarked, "Now that I think about it, I do think of parking farther away in the parking lot and taking the stairs instead of the elevator. But, do I do them? Not always. It does make an impression, though." Another drop-out said, "I need to change my physical activity. Nutrition isn't enough." 
Mid-achievers and high-achievers had many thoughts, and those were often positive and forward-thinking. For example, one participant mentioned that when there was an assignment asking him to write his goals, he could visualize five goals and think about how to achieve them.

The Life Assignments contained few written negative thoughts and an abundance of positive thoughts. The few negative thoughts were "change is not easy for me," "habits are hard to break," and "no will power." Positive thoughts were, "I understand that I can make this a life change," "I need to get off high blood pressure meds," and "I feel better when I'm active." When asked to write in one Life Assignment "Things that Help Me Succeed," one participant wrote, “This program," and "Joining a gym."

\section{Behaviors}

Although there were only 17 unique statements about behaviors, the theme Behavior is described here because interviewees were asked, "Did you feel that this program changed your behaviors or thoughts about physical activity?" ALED Online did not seem to change drop-outs behaviors with regard to physical activity. None of the three drop-outs mentioned a changed behavior in the interviews.

The high-achievers made many more references to behavior than any of the three sub-groups. They mentioned activities such as walking, working-out, swimming, and playing tennis. One high achieving interviewee remarked, "I play more tennis in the spring. Last year I mostly played doubles not singles. In the spring there will be a little less swimming and more tennis." Typical behaviors listed in the Life Assignments included: walking more, walk at lunch, working-out, preparing dinner, using stairs at 
work, cleaning, and shopping at mall. These types of changes to behavior are consistent with what would be expected with ALED, as opposed to formal exercise programs.

\section{Time}

Time was an important theme for the interviewees. There were 21 unique statements spoken about time in the interviews. Time could have been related to making time for physical activity, making time for the program, or making time for one's self. Time was often mentioned as a constraining factor. One mid-achiever said it best when asked about whether the program met her expectations:

I didn't get all my homework done, but yes. We have been so swamped with work. I go home and I crash. It would have been better if I did the program in the spring when I didn't have so much going on. We had Christmas and the holidays. And we have our own business. I just ran out of time.

When asked whether she had trouble incorporating more physical activity into her life, one drop-out said, "Yes, because in my instance, I'm a pleaser, so it's a habit-change thing. Making time to change for myself...everyone else's needs are more important than my own." She also discussed how it is difficult to be a parent and make time for herself.

In the Life Assignments, participants described how they spent their time. The best asset for triangulating the Time theme was the "My Personal Time Study" Life Assignment. Among all the Life Assignments, this was the assignment where participants spent the greatest number of minutes. The activities listed by the interviewees often demonstrated their perceived time constraints. Participants spent time 
engaged in computer/desk work, driving to work, watching television, reading the newspaper, reading mail, going to church, and attending to unplanned events.

\section{Facilitation}

There were 21 unique statements about the facilitator and how ALED Online was delivered. These comments were positive for each of the three sub-groups. In terms of facilitation, one participant said, "The weekly follow-up emails were good. The summary of what was coming was good." In terms of the facilitator, comments were also favorable. One participant said, "Working with you has been great. It's been comforting and helpful and I appreciate that. Some places you go, you hate to get on the scale, and I haven't felt that way with you." Another participant said,

It was the little things, like turning in an assignment and getting a 'way to go.' The niceties. It doesn't take a tremendous amount of time, but it was nice to get some kudos. A couple one-liners of something is nice to have for encouragement.

\section{Accountability}

Although there were just 13 unique statements about accountability, it seemed to be an important theme. In general, drop-outs favored more accountability, and mid- and high-achievers praised the amount of accountability that was built into the program or the research project, itself. A few participants mentioned Weight Watchers. One participant said, "Having a place like Weight Watchers to check-in would have been good. How many times were we supposed to meet? Four?" This participant continued, "I need to be accountable. I can be accountable for about a week." Another participant described how 
the scale used to weigh her in the study recorded a higher weight for her than her Weight Watchers scale at home.

An unexpected aspect of the study was the effect of the research project on accountability. Some participants seemed to identify the ALED Online program with the research project. The research project included measures of cholesterol and BMI. One high-achiever said, “I've got this new doctor, and he said as long as I'm willing to do the [ALED] program, he's willing to help me. Your program helped me find a physician who is willing to help me." She continued, “I can't wait for January 31 [our next oncampus meeting and weigh-in]. My goal is to lose $10 \%$ of my weight total."

In addition to talking about being weighed, participants talked at length about having their blood drawn. One participant said, "Something else that motivated me was seeing my cholesterol. The program helped by showing my bloodwork." Another participant praised the phlebotomist and the facility where her blood was drawn. Although this participant dropped out of the ALED Online program, she requested her remaining lab order forms so that she could continue to have her lipid profile examined and share the results with her physician. Accountability was something that participants were clearly looking for in ALED Online.

\section{Integrated Analyses of the Mixed Methodology}

High-achievers, mid-achievers, and drop-outs differed in their responses to the ALED Online intervention. For this integrated analyses, the process and product variables for purposefully selected interviewees are shared. Three high-achievers, two mid-achievers, and three drop-outs were selected to describe typical experiences of participants in ALED Online. Interviewees chose pseudonyms in order to protect their 
identities, but all other demographic information and dependent variable measures are portrayed precisely.

\section{High-Achievers}

There were three high-achievers identified who were chosen for the purposes of representing typical high-achievers. The high-achievers pseudonyms are Ann, Mark, and Precious.

Ann is a 48 year-old female who described her race/ethnicity as "mixed." She completed all 20 Life Assignment modules. Before beginning the program, her BMI was 34.3. $\mathrm{By}_{4}$, her BMI had improved to 31.9. Ann was particularly interested in seeing changes in her cholesterol. Her HDL cholesterol improved from 55 at the start of the study to 63 by the end of the study. Her LDL decreased favorably from 188 to 82 . From $\mathrm{O}_{1}$ to $\mathrm{O}_{2}$, Ann's HDL and LDL cholesterol improved slightly. However, between $\mathrm{O}_{2}$ and $\mathrm{O}_{3}$, Ann started taking cholesterol medication, and she had substantial improvements in her cholesterol over time. Ann sought-out accountability. She began discussing her cholesterol with her doctor. After conversations with her doctor and throughout participation in ALED Online, she made a dedicated effort to increase her physical activity. Her average daily steps at $\mathrm{O}_{1}$ were 6,158 (low active) and increased to 15,984 (highly active) at $\mathrm{O}_{4}$. Her SOC improved from preparation to action during the study, and that was reflected in her step count. During the $\mathrm{O}_{4}$ follow-up, Ann said that during the study's control condition she increased her physical activity and was thinking about "everything" she ate.

Mark is a 58 year-old Caucasian male. He also completed all 20 Life Assignment modules. His BMI remained relatively steady over the course of the program (ranging 
from 30.3 to 30.9 at various points. His $\mathrm{HDL}$ improved from 44 to 51 from $\mathrm{O}_{1}$ to $\mathrm{O}_{4}$. Likewise, his LDL improved from 122 to 100 from $\mathrm{O}_{1}$ to $\mathrm{O}_{4}$. During Mark's interview, he mentioned that he was quite active before beginning the study and continued to be active throughout the duration of the study. While Mark was already active, he appreciated how ALED Online reinforced his thoughts about physical activity. He mentioned that goal-setting activities were especially beneficial. Mark's step counts throughout the study were typically in the low active to active ranges. However, Mark recorded swimming in his physical activity log several times a week throughout the duration of the study, and did not wear a pedometer during those bouts of activity. During the $\mathrm{O}_{4}$ follow-up, Mark said that he had not increased or decreased his physical activity in the control condition. His SOC was maintenance throughout. When Mark was interviewed, he said that he felt the ALED Online program was more geared toward people who were just starting to become active.

Precious is a 43 year-old Caucasian female. Like Ann and Mark, Precious completed all 20 Life Assignment modules. Her BMI also remained consistent from $\mathrm{O}_{1}$ to $\mathrm{O}_{4}$ (ranging from 27.1 to 27.3). Although Precious was apprehensive about having her blood drawn, she completed all four lipid tests. From $\mathrm{O}_{1}$ to $\mathrm{O}_{4}$, her $\mathrm{HDL}$ improved from 44 to 51, and her LDL improved from 122 to 100 . Her SOC remained maintenance throughout the duration of the study. Precious's step counts were variable throughout the study. For $\mathrm{O}_{1}$, her step count was 7,351. Her step count worsened to 7,058 at $\mathrm{O}_{2}$, and she attributed that to being so busy at work during that week. While Precious didn't have reliable internet access at home, she was using her computer at work to log into the ALED Online website. She was able to overcome "ease of use" barriers as long as she 
was not too busy at work. At $\mathrm{O}_{3}$, her step count had improved to 7,764. But during the control condition, Precious's step count had fallen to 6,962.

As a group, the high-achievers performed well (see Table 1). They completed all 20 weekly ALED modules. They used the online course an average of 277.99 minutes (or 4.6 hours). They visited, on average, 66.67 Non-Tool resources pages. They remained low active over time. Their BMI remained steady or improved. As a group of high-achievers, they saw improvements in cholesterol and SOC. From $\mathrm{O}_{1}$ to $\mathrm{O}_{4}$, their HDL improved, on average, from 47.66 to 55.00. From $\mathrm{O}_{1}$ to $\mathrm{O}_{4}$, their LDL improved, on average, from 144.00 to 94.00 . Their SOC either improved to action or remained maintenance throughout the study.

\section{Mid-Achievers}

There were two mid-achievers identified who were chosen for the purposes of representing typical mid-achievers. The mid-achievers pseudonyms are Barbie Doll and Sophia.

Barbie Doll identified herself as a 47 year-old white female. She completed 10 Life Assignment modules. Barbie's BMI was relatively consistent over the course of the study, ranging from 25.9 to 26.6. From $\mathrm{O}_{1}$ to $\mathrm{O}_{3}$, her HDL and LDL fluctuated, and she did not have her cholesterol checked on $\mathrm{O}_{4}$. Barbie's HDL levels were 56, 66, and 60 and her LDL levels were 146, 185, and 151. Her self-reported SOC improved from action to maintenance during the study. Barbie walks with co-workers most days of the week. She rationalizes her participation in physical activity by reflecting on her weight loss, how well her clothing fits, and how much improved her skin appears. Barbie's step count improved from $\mathrm{O}_{1}$ to $\mathrm{O}_{3}$, with 6,064, 6,105, and 7,326, respectively. Barbie's step 
count fell to 4,450 during the control condition, but she reported that she had been sick then.

Sophia is a 62 year-old Caucasian female. She completed 11 Life Assignments. Sophia's BMI improved somewhat during the intervention. From $\mathrm{O}_{1}$ to $\mathrm{O}_{3}$, her BMI decreased from 25.3, 25.2, and 24.1, respectively. $\mathrm{By}_{4}$, her BMI had increased slightly to 24.5. From $\mathrm{O}_{1}$ to $\mathrm{O}_{3}$, Sophia's HDL improved from 87 to 105 , but worsened to 86 in the control condition. Likewise, her LDL improved from $\mathrm{O}_{1}$ to $\mathrm{O}_{3}$, from 71 to 60 , but increased slightly to 61 in the control condition. Sophia's self-reports of SOC improved from preparation to maintenance. Her step count from $\mathrm{O}_{1}$ to $\mathrm{O}_{4}$ improved from 4,737, $6,598,5,099$, and 6,820. When asked to complete her personal time study, Sophia recorded a number of physical activities such as walking and cleaning. She mentioned that time was often a constraining factor for her.

As a group, the mid-achievers performed reasonably well from $\mathrm{O}_{1}$ to $\mathrm{O}_{3}$ (see Table 2). Adherence to ALED Online was better early in the program, but Life Assignment completion rates dropped-off over time. They completed an average of 10.5 weekly ALED modules. They used the online course an average of 306.78 minutes (or 5.11 hours). They visited, on average, 43.5 Non-Tool resources pages. Their step count from $\mathrm{O}_{1}$ to $\mathrm{O}_{3}$ improved from an average of 5,400 to $6,212.5$, but they remained low active. There were no apparent changes in BMI. They did see improvements in cholesterol and SOC. From $\mathrm{O}_{1}$ to $\mathrm{O}_{3}$, their HDL improved, on average, from 71.50 to 82.50. From $\mathrm{O}_{1}$ to $\mathrm{O}_{3}$, their LDL improved slightly from 108.5 to 105.50 . Their SOC improved, on average, 1 stage, from preparation to action, and action to maintenance. 


\section{Drop-outs}

There were three drop-outs identified who were chosen for the purposes of representing typical drop-outs. The drop-outs' pseudonyms are Emma, Estelle, and Susie Q.

Emma described herself as a 36 year-old white female. She completed 3 Life Assignment modules. Emma attended the first on-campus meeting $\left(\mathrm{O}_{1}\right)$, but did not return for subsequent testing occasions. On $\mathrm{O}_{1}$ her BMI was 43.2. Emma's HDL was desirable at 51, but her LDL was 132. Her SOC was contemplation, and her average daily step count was 3,173 (sedentary). Emma dropped out of the study for health reasons, but in the interviews she confided that she just needed to make time for herself to get healthier.

Estelle is a 67 year-old Caucasian female. She completed 3 Life Assignments, but had difficulty saving her work and attaching the documents to email. During the interview, she said that it wasn't too much of an issue, but it did delay her submissions to the facilitator. Like Emma, Estelle only attended the first on-campus meeting. On $\mathrm{O}_{1}$ her BMI was 29.6. Her HDL and LDL cholesterol numbers were desirable at 60 and 88, respectively. Her SOC was preparation. On $\mathrm{O}_{1}$, Estelle was low active with 7,330 average daily steps. Although Estelle's physician encouraged her to participate in the program, ultimately she rationalized dropping-out for health reasons. When asked whether the program met her expectations, Estelle replied, "No." She thought the program would help her learn to work around her rheumatoid arthritis and allergies.

Susie Q. is a 34 year-old white female. She completed 5 Life Assignment modules. Susie Q. provided data for BMI, $\mathrm{SOC}$, and step count for $\mathrm{O}_{1}$ to $\mathrm{O}_{3}$, data for 
LDL and HDL for $\mathrm{O}_{1}$ and $\mathrm{O}_{2}$, and no data for $\mathrm{O}_{4}$. Susie's BMI decreased slightly from $\mathrm{O}_{1}$ to $\mathrm{O}_{3}$ from 36.4 to 35.8 . Her self-reported $\mathrm{SOC}$ improved from preparation to action, but her step counts decreased from 10,293, 8,742, and 7,855, respectively. Her HDL improved slightly from 51 to 53, and her LDL improved slightly from 120 to 116.

During the study, Susie was enrolled in an aerobics class. She tore a ligament in her foot, and dropped-out of the study before the fourth testing occasion. Overall, Susie wanted more accountability from ALED Online.

Because two of the three drop-outs only reported to campus for $\mathrm{O}_{1}$, and the third drop-out had missing data on $\mathrm{O}_{2}$ and $\mathrm{O}_{3}$, their data for $\mathrm{O}_{1}$ is summarized here and in Table 3. On average, drop-outs completed 4.33 Life Assignment modules. They used the online course an average of minutes 135.65 (or 2.26 hours). They visited, on average, 30.33 Non-Tool resources pages. Their average BMI for $\mathrm{O}_{1}$ was 36.4. Their HDL was desirable, and averaged 54.00. Their LDL was averaged 112.00. Their step count for $\mathrm{O}_{1}$ was 6,932 (low active). Their SOC ranged from contemplation to action.

\section{Summary of Integrated Analyses}

Some of the differences in BMI, SOC, LDL cholesterol, HDL cholesterol, and step count for each of the sub-groups might be explained by examining how these groups differed with respect to the emergent themes. The seven themes that emerged from the interviews were Time, Accountability, Facilitation, Ease of Use, Rationalization, Thoughts, and Behaviors.

During the interviews, high-achievers said more per person than mid-achievers and drop-outs. High-achievers averaged 34.65 statements, mid-achievers averaged 24.5 statements, and drop-outs averaged 17.65 statements that related to the themes. By 
theme, high-achievers made fewer statements about time constraints than mid-achievers or drop-outs. High-achievers averaged 2.33 statements, mid-achievers averaged 2.5 statements, and drop-outs averaged 3 statements per person about time constraints. Likewise, high-achievers made fewer statements per person about accountability. Highachievers only made 1.33 statements about accountability, whereas the drop-outs made 2.33 statements per person about accountability. In general, drop-outs expected more accountability from the ALED Online program.

There were distinct differences among the groups when examining the themes Ease of Use, Rationalization, Thoughts, and Behaviors. For Ease of Use, drop-outs made 4.33 statements per person, whereas high-achievers made 8.33 statements per person. While high-achievers may have had technical issues with the website that were similar to the drop-outs, they identified solutions or provided suggestions for improving the usefulness of the program. For the theme Rationalization, drop-outs made 4.33 statements per person, mid-achievers made 9.5 statements per person, and high-achievers made 8.0 statements per person. Typically, the way drop-outs described their failures were in defeatist language, whereas high-achievements spoke about positive reasons for staying with the program.

The Thoughts and Behaviors themes are most distinct for each of the sub-groups. Interviewees were asked whether the ALED Online program changed their thoughts or behaviors toward physical activity. For Thoughts, drop-outs had just 1.33 statements per person about Thoughts, mid-achievers had 3.5 statements, while high-achievers had 7.0 statements about Thoughts. In terms of Behaviors, there were 0 statements about Behavior by the drop-outs, 1.5 per person for mid-achievers, and 4.66 for high-achievers. 
These results may have important implications for examining changes in the dependent variables of interest. Among research adherents, SOC, HDL, and LDL improved. Examining themes in conjunction with measures of the dependent variables demonstrated how the intervention changed participants' thoughts or behaviors in relation to physical activity. 


\section{CHAPTER 5}

\section{DISCUSSION}

The purpose of this study was to examine the effects of a 14-week intervention based on Active Living Every Day (ALED) Online. Products of the 14-week online program and the process of delivering the program are summarized. Product considerations included: whether ALED Online increased physical activity among participants (as measured through step counts), whether physiological changes (cholesterol and body mass index) were apparent throughout the intervention, and whether participants in ALED Online progressed or regressed through the Stages of Change (SOC). Process measures included examining the nature of retention of participants in the study and the quality of participants' responses to the "Life Assignments" homework component of ALED Online. The purpose of this chapter is to describe the study's product and process evaluations, and to summarize the study's strengths, limitations, and suggested future directions.

\section{Product Evaluation}

There were three major research questions for the present investigation. These questions were: (1) Does ALED Online increase physical activity? (2) What physiological changes (cholesterol and BMI) are evident prior to the intervention, during the intervention, and after the intervention has been completed? and, (3) Do participants in ALED Online progress or regress through the SOC?

There were no statistically significant multivariate intervention effects for the 21 participants who started the program. However, for those participants who completed the ALED Online research project, there were statistically significant intervention effects 
found at the multivariate level. Changes regarding participants' physical activity, physiological indicators, and SOC will be described.

\section{Physical Activity}

To answer the first research question "Does ALED Online increase physical activity?" pedometers were used to record average daily step counts in order to approximate physical activity. There were no statistically significant differences in step count for the group at-large, nor were there any intervention effects on physical activity for research adherents. This runs counter to the research hypothesis that predicted "participants in the study will increase their physical activity." Wilcox et al. (2006) found increases in physical activity among their participants in ALED Online. While Dunn et al. (1997) found that men enrolled in ALED's forerunner Project Active increased overall physical activity and vigorous physical activity, the researchers conceded that these results were not statistically significant.

An important consideration in measuring changes in physical activity is the selection of the tools used to assess potential changes. In this investigation, pedometers were used to approximate physical activity. A number of studies have found pedometers are reliable for physical activity research (Bassett et al., 1996; Tryon, Pinto, \& Morrison, 1991).

Tudor-Locke and Bassett (2004) have suggested indices for classifying physical activity by step count. They suggest $<5,000$ steps per day is sedentary, $5,000-7,499$ is low active, 7,500-9999 is somewhat active, $>10,000$ steps is active, and $>12,500$ is highly active. Using Tudor-Locke and Bassett's suggested indices, participants in the present study were low active and somewhat active. 
However, pedometers measure ambulatory activity. There were participants in the present investigation who swam and rode bicycles throughout each of the four data collection periods. Physical activity for those instances may not have been recorded by pedometers.

It is possible there were seasonal intervening variables which may have affected physical activity. This intervention was conducted from the months September through January. During the semi-structured interviews, participants commented on increases in workload in the fall, the holidays, and not doing as much when the weather is colder. It is possible that poor weather in the fall and winter months affected participants' willingness to increase their physical activity. This is consistent with the findings of Buchowski et al. (2009) and Reilly and Peiser (2006) who reported that physical activity is lower in the winter and significantly higher in the summer and spring.

\section{Physiological Indicators}

The purpose of the second research question was to determine whether there were changes in body mass index (BMI), LDL cholesterol, and HDL cholesterol. For research adherents, there were no statistically significant changes for BM1. This may not be surprising, however, since the purpose of ALED is to help participants learn to incorporate physical activity into their daily lives (Cooper Institute, n.d.). Small behavioral changes in physical activity (rather than vigorous amounts of physical activity) may not be enough to significantly affect BMI. According to the U.S. Department of Health and Human Services (2008), “There are clear, consistent data that a large volume of physical activity is needed for weight loss in the absence of concurrent dietary changes" (p. 93). 
Although BMI was not affected by ALED Online, research adherents saw improvements in LDL and HDL cholesterol. It was hypothesized that participants in the present investigation would see improvements in LDL and HDL since Carr et al. (2008) and Dunn et al. (1997) saw significant improvements in total cholesterol/HDL-C, LDL, and HDL. The findings related to cholesterol here were consistent with the findings of Carr et al. (2007) and Dunn et al. (1997).

For the research adherents, it seems confounding that there were no statistically significance differences in BMI or physical activity, but LDL and HDL cholesterol improved. To address this, research adherents were asked questions (that were qualitative in nature) to describe personal health changes during the control condition (see Appendix D). The research adherents were asked whether they were eating any differently than they were "seven weeks ago." Ten of the 11 respondents answered "yes" to that question. When asked to describe how they were eating differently, participants mentioned decreasing portion size, watching carbohydrate intake, joining Weight Watchers, and eating more fruits and vegetables. While the ALED Online study was primarily concerned with physical activity, this insight into nutrition could shed light on changes in participants' cholesterol.

\section{Stage of Change}

Stage change was an important consideration in the present investigation. ALED was based upon the Transtheoretical Model and the SOC construct (Cooper Institute, 2006), so evaluating participants' SOC was essential. Programs that use stage of change produce better outcomes than those that do not (Noar, Benac, \& Harris, 2007). However, 
a product evaluation examining stage change on ALED Online has not (as yet) been documented.

For the present investigation, the research adherents saw statistically significant positive changes in SOC. Research adherents advanced (on average) from the preparation stage to the action stage. This is important because people who advance through SOC are engaging in more physical activity. Those in the lower levels of the SOC construct (pre-contemplation and contemplation) typically have poorer self-efficacy than people who are in the upper levels of the construct (action and maintenance) (Lippke \& Plotnikoff, 2006). Because a number of the intervention's drop-outs were in the contemplation and preparation stages, it is possible that the drop-outs' self-efficacy toward successful completion of the program was diminished. A facilitator should consider the degree to which a potential participant's stage of readiness to make behavior change affects his/her thoughts and self-efficacy toward participating successfully in an online physical activity intervention.

\section{Process Evaluation}

Because online learning in physical activity is a novel approach, the manner in which online programs are delivered should be evaluated. Of primary concern for the ALED Online research project was the process of delivering the program. Life Assignments and semi-structured interview transcripts were examined in order to evaluate the process of delivering ALED Online. What follows are suggestions for Needs Assessment and Planning, Program Implementation, and Program Evaluation. 


\section{Needs Assessment and Planning}

Before making a decision about delivering ALED, facilitators may consider conducting a needs assessment to determine personal preferences and abilities. ALED facilitators may consider whether they prefer a 14-week or 20-week format, and whether they prefer a traditional, in-class or online mode of delivery. If a facilitator makes a decision to offer ALED in an online format, "The teacher should be able to troubleshoot his or her technical problems and also help students with technological problems and issues that arise during the course" (NASPE, 2007, p. 6). For this present investigation, Active Living Partners provided extensive training and offered ongoing technical support prior to and throughout the program.

Concurrently, a facilitator should consider the needs of potential program participants. Facilitators of online physical activity interventions would be well-served to consider their participants' willingness to participate in a non-traditional approach, their technological abilities, and their access to reliable internet and email service. Targeted marketing using email, online postings, or employer-sponsored employee wellness or insurance outreach efforts are suggested. ALED Online may work best with participants who are willing to respond to electronic queries. A number of participants in this investigation responded to a press release delivered through West Virginia University's E-News (sent via email) and through the University’s Employee Wellness Program.

If a potential participant expresses interest in taking an online physical activity course, minimal competencies for participants might include knowing how to get online, knowing how to compose an email message, knowing how to attach a document (or homework) to an email message, or using chat rooms/discussion groups. While these 
skills may seem simple, they were sometimes problematic for one of the older participants in the present investigation.

It's suggested that prior to implementing an online program, participants should meet with the facilitator to review the technological abilities needed for participation. Participants should be comfortable knowing how they will interact with their facilitator. If a potential participant expresses frustration with using the internet or email prior to the intervention, that information should be used for program planning purposes.

Participants' outcome expectancy should also be explored prior to the intervention. Participants should be asked what they expect to get out of the program, and what barriers they can foresee as problematic. In the present study, for example, one mid-achiever reported problems with accessing ALED Online from her home. After troubleshooting, a plan was formulated where she would print her Life Assignments at work and deliver hard-copies to the facilitator. Conducting needs assessments helps to troubleshoot problematic situations before they arise.

\section{Program Implementation}

The generation of qualitative themes for this study indicates that the ability to implement ALED Online effectively is largely dependent upon the thoughts of the participants and the disposition of the facilitator. How participants rationalized their participation in or withdrawal from the study was important. Participants who persisted in the program rationalized their behavior in positive terms, whereas drop-outs' comments were sometimes negative in nature. Drop-outs and mid-achievers were more likely to believe that ALED Online would teach them how to work around their unique health issues. While drop-outs and mid-achievers may have completed Life Assignments 
early in the intervention, their Life Assignment completion rate dropped-off as the study progressed.

It is important for a facilitator to consider participants' expectations during program implementation. As a facilitator sees that assignment completion is waning, she should explore the thoughts of the participants. Active Living Partners provides phone scripts for facilitators to use to call participants throughout the program. Placing phone calls to participants throughout the program may help a facilitator see whether participants' thoughts are becoming negative and how they are rationalizing their participation (or lack of participation) in the program.

Some participants in this study felt that completing the Life Assignments and emailing them to the facilitator was "redundant" or "repetitive." A facilitator should frequently reiterate the importance of completing assignments so that individuals are empowered to make their own personal behavior changes. NASPE (2007) suggests, "The teacher should use appropriate instructional strategies, provide clear expectations to students, interact frequently, monitor student work, offer immediate and specific feedback, and provide support and resources to students" (p. 6).

In the present investigation, social support was provided through the facilitator, but not by other participants enrolled in the research project. This lack of social support could have limited participants' enthusiasm for the program. A program facilitator or physical educator delivering online physical activity content may be able to provide some degree of social support, but the facilitator's support, alone, may not be effective. In order to create meaningful social interaction between facilitators and participants and among participants and their peers, threaded discussions and small group chat room 
groups are promising approaches (Curtis, 2004). The use of chat rooms, online discussion boards, and social networking sites are recommended as strategies for enhancing social support, particularly in ALED Online.

In spite of the popularity of chat rooms, online discussion boards, and social networking sites, there remain issues concerning the "digital divide." The digital divide typically refers to a lack of internet access among those with low socioeconomic status or those who live in geographically remote areas (Stellefson, Chaney, \& Chaney, 2008). In the present investigation, four of the eight interviewees expressed problems with internet access, and one participant in the pilot study experienced similar barriers to access. Two of the four interviewees lived in rural areas. These two participants were using dial-up modems to access the ALED Online course material. The other two interviewees living in rural areas discussed how they would try to "steal time" at work to log-in because internet access was more reliable at work than it was at home.

The Ease of Use theme emerged from the qualitative analyses of the process measures for the study. Throughout the study, the facilitator responded promptly to issues, concerns, or suggestions about how to use the website most effectively. However, having reliable internet access and expressing a preference for using a book to complete homework assignments may be more important for retention than receiving prompt online help from the facilitator.

\section{Program Evaluation}

Evaluating the effects of ALED Online was challenging. It was apparent that ALED was developed as a 20-week, traditional, classroom-based course. For this study, all 20 modules for ALED Online were delivered in the 14-week format prescribed by 
Active Living Partners. The weekly delivery of the content was done with fidelity, but there were required activities that could not be assigned in a manner consistent with the traditional classroom format. For example, classroom-based activities that should have been done with classmates could not be completed by participants enrolled in the online course. In these instances, accountability was lacking because participants did not rely upon others in the group for collaboration and support.

The online version of ALED may be hampered by a lack of social support that could be found in a traditional classroom setting. One high-achiever remarked, "I never saw the other people there were in the program. I would have liked to have seen them...not to compete, but to share or encourage them." It is possible that retention of subjects in the online program was hampered by a perceived lack of social support.

Because research participants did not interact with each other, and their in-person interaction with the facilitator was limited to four data collection points, it is possible that there was less perceived accountability in ALED Online. In general, drop-outs were seeking more accountability, whereas mid- and high-achievers praised the amount of accountability that was built into the program or the research project, itself. A few participants mentioned weekly weigh-ins at Weight Watchers as being helpful. One potential solution to the problems of social support and accountability with ALED Online would be to create a hybrid or blended model of instruction, where participants would meet in person a prescribed number of times throughout the program (perhaps 4 times), complete their Life Assignments online, and collaborate with others via small online discussion groups. 
In terms of research, interventions having more contact with participants and interventions with messages tailored to the target audience are most effective (Marcus, Owen, Forsyth, Cavill, \& Fridinger, 1998). It would be reasonable to assume that programs that require facilitators to contact participants frequently with tailored messages would be more effective than those program facilitators who provide infrequent, untailored comments. Facilitators of ALED Online should be encouraged to use the phone scripts provided by Active Living Partners.

It would also be reasonable to assume that participants who meet with facilitators more frequently see positive health changes. The efficacy of the traditional 20 -week ALED course has been documented (Dunn et al., 1998; Wilcox et al., 2006). Early research in ALED (which included a 6-month intensive program and 18 months of "maintenance" intervention) produced significant improvements in physical activity, body fat, and cardiovascular health (Dunn et al., 1997). To some extent, these changes were not realized in the present investigation. Overall, there were no statistically significant differences in physical activity or BMI, for example. However, among research adherents, there were positive changes in HDL and LDL cholesterol (which are indicators for cardiovascular health). Like the Carr et al. (2008) study, improvements in cardiovascular health were realized, even though participants may not have logged into the website on a weekly basis. Accountability should be built into online programs, whereby participants "check-in" with their group to share successes and seek support. 
Strengths, Limitations, and Future Directions

Strengths of the Research

There are a number of strengths in the investigation of ALED Online that are particularly noteworthy. Primarily, a major strength of this investigation is that the ALED program, itself, is based upon extensive research (Dunn et al., 1997; Dunn et al., 1998; Wilcox et al., 2006) and a sound theoretical framework (Prochaska \& Velicer, 1997; Pro-Change Behavior Systems, 2007). ALED has evolved over time as empirical evidence has been produced by researchers and facilitators. Further, Active Living Partners require extensive training and successful completion of coursework before facilitators or directors are certified to be providers of ALED content.

The purpose of ALED is to encourage participants to include moderate amounts of physical activity into their daily lives. For that reason, the primary research question for this study was to determine whether participants enrolled in ALED Online increased their physical activity. While participants in this study did not increase physical activity, the data collection methods were sound. Yamax Digi-Walker pedometers recorded step count on seven consecutive days on four separate occasions. A number of studies have found pedometers are reliable for physical activity research (Bassett et al., 1996; Tryon, Pinto, \& Morrison, 1991); and, wearing a pedometer for just 5 to 6 days is long enough to obtain data that represents "usual" physical activity (Gretebeck \& Montoye, 1992).

In addition to evaluating physical activity, other dependent variables of interest included HDL cholesterol, LDL cholesterol, SOC, and BMI. The strengths of the quantitative, multivariate repeated measures included examining the effects of the 
intervention on physical activity, HDL, LDL, SOC, and BMI at multiple points throughout the study.

Measurements of dependent variables remained consistent throughout the intervention. This study's internal validity was strengthened through the use of repeated measures on the same participants over four testing occasions. Each participant had physiological measures taken during the Recruitment Phase, at Week 7, at Week 14 and at Week 21 of the study. All lipid panel analyses were performed on each testing occasion by one laboratory following standard phlebotomy practices. SOC was measured consistently using the Stage of Change decision tree provided through the ALED course material. Measures of BMI were derived by taking all height measurements using one stadiometer, and weight measures were done using the same scale for the participants on all four occasions. When drop-outs were excluded from the repeated measures multivariate analysis of variance (MANOVA), it appeared that changes in HDL cholesterol, LDL cholesterol, and SOC for the research adherents were the direct result of the intervention.

Using a mixed method, quantitative-qualitative approach seems to have helped address potential threats to validity. Using multiple methods of data collection was beneficial for addressing reasons there were or were not changes in the dependent variables of interest. The interview data and Life Assignment data were particularly helpful for describing how each sub-group (drop-outs, mid-achievers, and highachievers) fared in the program. 


\section{Limitations of the Research}

This inquiry into the value of ALED Online was constrained by three major factors. These factors included participant attrition, time, and sample size. Participant attrition (or mortality) was particularly problematic from the third testing occasion through the control condition. Retention of participants from the completion of the intervention $\left(\mathrm{O}_{3}\right)$ through the control condition $\left(\mathrm{O}_{4}\right)$ may have been hampered because participants were not provided with tangible incentives for completing all four testing occasions. Participants may not have felt engaged in the research once they completed the 14-week program. Participants were contacted through email reminding them about upcoming assessment dates. However, the length of time in the control condition may have affected attrition.

Participants in the present investigation were asked to comply with the research protocol for 21 weeks. Carr et al. (2008) found that "lack of time" was primary reason for dropping out of their study. Carr et al. found attrition rates of $23 \%$ in one study, and $51 \%$ in their second study. The authors found less attrition among older participants. The authors speculated that this may have been due to the amount of time older participants had available to participate, greater readiness to change, and greater motivation to change due to the participants' advanced age and risk factors.

Because of participant attrition throughout the 21 weeks in the present investigation, the ability to establish that there were lasting intervention effects for the entire group was limited. While there were positive results for participants who adhered to the research protocol, these results should not be generalized beyond the scope of an online physical activity intervention. Likewise, these results would not necessarily 
predict changes in the dependent variables to a different population of ALED Online users.

Suggestions for Future Directions

There has been a tremendous increase in the number of distance learning opportunities in physical activity over the past decade (Strecker, 2008), but researchbased examinations of these programs are relatively limited. There are data to suggest that physical activity interventions based upon theoretical frameworks are effective (Pinto et al. 2002; Vandelanotte, Bourdeaudhuij, Sallis, Spittaels \& Brug, 2005; Spittaels, Bourdeaudhuij, \& Vandelanotte, 2007; Marcus, Owen, Forsyth, Cavill, \& Fridinger, 1998), but questions remain about the nature of online learning.

Results of this study of ALED Online suggest that more research in the area of the Transtheoretical Model and SOC, in particular, is warranted. Future researchers may consider whether participants in the lower stages (pre-contemplation and contemplation) are, indeed, more likely to drop-out.

Researchers may experiment with a variety of instructional strategies try to keep potential drop-outs enrolled in ALED Online. For example, some interviewees in this study expressed a desire for more accountability from the program. It may be that participants enrolled in an online physical activity program feel less accountable because there is a lack of direct contact between the participant, his/her fellow participants, and the facilitator. A hybrid or blended model of instruction (with part of the class delivered online and part of the class delivered in person) may prove to be an attractive strategy for encouraging accountability and compliance. 
More research into online learning in physical activity, in general, is recommended. A number of school districts, universities, health care providers, insurers, and governmental entities are promoting web-based programs. Online learning in physical activity and physical education is a non-traditional approach to pedagogy. While "online physical education is neither inherently good nor bad...the value of any educational technology or pedagogical strategy must always broach the question of learning" (NASPE, 2007, p. 1). The value of any technology or pedagogical approach should also be evaluated by the users or participants. Examining physical activity and physiological changes are important, but studies that also take into account the perspectives of participants are encouraged. 


\section{REFERENCES}

Active Living Partners. (2008). Active Living Every Day facilitator training.

Champaign, IL: Human Kinetics.

Active Living Partners. (2002). Active living every day facilitator guide. Champaign, IL: Human Kinetics.

American College of Sports Medicine. (2000). ACSM's Guidelines for exercise testing and prescription. Baltimore, MD: Lippincott, Williams, and Wilkins.

American Diabetes Association. (n.d.). All about diabetes. Retrieved February 12, 2007, from http://www.diabetes.org/about-diabetes.jsp

Bassett, D.R., Ainsworth, B.E., Leggett, S.R., Mathien, C.A, Main, J.A., Hunter, D.C, \& Duncan, G.E. (1996). Accuracy of five electronic pedometers for measuring distance walked. Medicine and Science in Sports and Exercise, 28, 1071-1077.

Bassett, D.R., Ainsworth, B.E., Swartz, A.M. Strath, S.J., O’Brien, W.L., \& King, G.A. (2000). Validity of four motion sensors in measuring moderate intensity physical activity. Medicine and Science in Sports and Exercise, 32, S471-S480.

Bassett, D.R., Cureton, A.L., \& Ainsworth, B.E. (2000). Measurement of daily walking distance-questionnaire versus pedometer. Medicine and Science in Sports and Exercise, 32, 1018-1023.

Blair, S., \& Church, T. (2004). The fitness, obesity, and health equation: Is physical activity the common denominator? [Electronic version] Journal of the American Medical Association, 292, 1232-1234.

Blair, S.N., Dunn, A.L., Marcus, B.H., Carpenter, R.A., \& Jaret, P. (2001). Active living every day: 20 steps to lifelong vitality. Champaign, IL: Human Kinetics. 
Bowman, T.S., Kurth, T., Sesso, H.D., Manson, J.E., \& Gaziano, J.M. (2007). Eightyear change in body mass index and subsequent risk of cardiovascular disease among healthy, non-smoking men. Preventive Medicine, 45, 436-441.

Buchowski, M.S., Choi, L., Majchrzak, K.M., Acra, S., Matthews, C.E., \& Chen, K.Y. 2009). Seasonal changes in amount and patterns of physical activity among women. Journal of Physical Activity and Health, 6, 252-261.

Canadian Society for Exercise Physiology. (1994). Physical activity readiness questionnaire. Health Canada.

Carr, L.J., Bartee, R.T., Dorozynski, C., Broomfield, J.F., Smith, M.L., \& Smith, D.T. (2008). Internet-delivered behavior change program increases physical activity and improves cardiometabolic disease risk factors in sedentary adults: Results of a randomized controlled trial. Preventive Medicine,46, 431-438.

Chenoweth, D. (2001). Sitting around, burning money. Business and Health,19(2), 27-28.

Chenoweth, D., DeJong, G., Sheppard, L. \& Lieber, M. (2003). The economic cost of physical inactivity in Michigan. Executive summary for the Michigan Fitness Foundation. Retrieved April 15, 2008 from http://www.michiganfitness.org/indexpagedownloads/CostofInactivity.pdf.

Cooper Institute. (n.d.). Active Living Partners. Retrieved December 12, 2006, from http://www.activeliving.info/featuredCourses.cfm.

Creswell, J.W. (2005). Evaluation research: Planning, conducting and evaluating quantitative and qualitative research. Upper Saddle River, NJ: Pearson Education.

Creswell, J.W. (2003). Advanced mixed method research designs. In A. Tashakkori \& 
C. Teddlie (Ed.). Handbook of mixed-methods in social and behavioral research. Thousand Oaks, CA: Sage.

Curtis, R. (2004). Analyzing students" conversations in "chat room” discussion groups. College Teaching, 52, 143-148.

Cyarto, E.V., Myers, A.M., \& Tudor-Locke, C. (2004). Pedometer accuracy in nursing home and community-dwelling older adults. Medicine and Science in Sports and Exercise, 36, 205-209.

Daley, A.J., \& Duda, J.L. (2006). Self-determination, stage of readiness to change for exercise, and frequency of physical activity among young people. European Journal of Sport Science, 6, 231-243.

Dunn, A.L., Marcus, B.H., Kampert, J.B., Garcia, M.E., Kohl, H.W., \& Blair, S.N. (1997). Reductions in cardiovascular disease risk factors: 6-month results from Project Active. Preventive Medicine, 26, 883-892.

Dunn, A.L., Marcus, B.H., Kampert, J.B., Garcia, M.E., Kohl, H.W., \& Blair, S.N. (1999). Comparison of lifestyle and structured interventions to increase physical activity and cardiorespiratory fitness. Journal of the American Medical Association, 281, 327-334.

Dunn, A.L., Garcia, M.E., Marcus, B.H., Kampert, J.B., Kohl, H.W. III \& Blair, S.N. (1998). Six-month physical activity and fitness changes in Project Active, a randomized trial. Medicine and Science in Sports and Exercise, 30, 1076-1083.

Field, A. (2005). Discovering statistics using SPSS. London: Sage Publications. 
Foreyt, J.P., \& Poston, W.S. (1999). The challenge of diet, exercise and lifestyle modification in the management of the obese diabetic patient. International Journal of Obesity, 23, 5-11.

Garrett, N., Brasure, M., Schmitz, K., Schultz, M., \& Huber, M. (2004). Physical inactivity cost to a health plan. American Journal of Preventive Medicine, 27, 304-309.

Glaser, B., \& Strauss, A. (1967). The discovery of grounded theory. Chicago, IL: Aldine.

Gretebeck, R., \& Montoye, H. (1992). Variability of some objective measures of physical activity. Medicine and Science in Sports and Exercise, 24, 1167-1172.

Hubert, H.B., Feinleib, M., McNamara, P.M., \& Castelli, W.P. (2009). Obesity as an independent risk factor for cardiovascular disease....a 26-year follow-up of participants in the Framingham Heart Study. Retrieved March 19, 2009, from http://circ.ahajournals.org.

Jackson, R., Asimakopoulou, K., \& Scammell, A. (2007). Assessment of the transtheoretical model as used by dieticians in promoting physical activity in people with type 2 diabetes. Journal of Human Nutrition and Diet, 20, 27-36.

Janssen, I. (2007). Physical activity, fitness, and cardiac, vascular, and pulmonary morbidities. In C. Bouchard, S.N. Blair, \& W.L. Haskell (Ed). Physical activity and health. Champaign, IL: Human Kinetics.

Kim, Y.H. (2006). Application of the transtheoretical model to identify psychological constructs influencing exercise behavior: A questionnaire survey. International Journal of Nursing Studies, 44, 936-944. 
LeMasurier, G.C., Lee, S.M., \& Tudor-Locke, C. (2004). Motion sensor accuracy under controlled and free living conditions. Medicine and Science in Sports and Exercise, 36, 905-910.

Lippke, S., \& Plotnikoff, R.C. (2006). Stage of change in physical exercise: A test of stage discrimination and nonlinearity. American Journal of Health Behavior, 30, 290-301.

Marcus, B.H., Nigg, C.R., Riebe, D., \& Forsyth, L.H. (2000). Interactive communication strategies: Implications for population-based physical activity promotion. American Journal of Preventive Medicine, 19, 121-126.

Marcus, B.H., Owen, N., Forsyth, L.H., Cavill, N.A., \& Fridinger, F. (1998). Physical activity interventions using mass media, print media, and information technology. American Journal of Preventive Medicine, 15, 362-378.

Miilunpalo, S., Nupponen, R., Laitakari, J., Marttila, J., \& Paronen, O. (2000). Stages of change in two modes of health-enhancing physical activity: Methodological aspects and promotional implications. Health Education Research, 15, 435-448.

National Association for Sport and Physical Education. (2007). Initial guidelines for online physical education: A position paper from the National Association for Sport and Physical Education. Reston, VA: American Alliance for Health, Physical Education, Recreation, and Dance.

National Institutes of Health. (2009). Qualitative methods in health research: Opportunities and considerations in application and review. Retrieved February 6, 2009 from http://www.nih.gov/icd/.

National Institutes of Health. (1998). Clinical guidelines on the identification, 
evaluation, and treatment of overweight and obesity in adults: The evidence report. Obesity Research, 6, S51-S210.

Nelson, T.E., Leenders, N.Y.J.M., \& Sherman, W.M. (1998). Comparison of activity monitors worn during treadmill walking. Medicine and Science in Sports and Exercise, 30, S11 [Abstract].

Noar, S.M., Benac, C.N., \& Harris, M.S. (2007). Does tailoring matter? Meta-analytical review of tailored health print behavior change interventions. Psychological Bulletin, 4, 673-693.

Pate, R.P. (2007). Historical perspectives on physical activity, fitness and health. In C. Bouchard, S.N. Blair, \& W.L. Haskell (Ed). Physical activity and health. Champaign, IL: Human Kinetics.

Patton, M.Q. (2002). Qualitative research and evaluation methods. Thousand Oaks, CA: Sage Publications.

Pinto, B.M., Friedman, R., Marcus, B.H., Kelley, H., Tennstedt, S., \& Gillman, M.W. (2002). Effects of a computer-based, telephone-counseling system on physical activity. American Journal of Preventive Medicine, 23, 113-120.

Physical Activity Guidelines Advisory Committee. (2008). Physical activity guidelines advisory committee report, 2008. Washington, DC: U.S. Department of Health and Human Resources.

Pro-Change Behavior Systems. (2007). Transtheoretical model. Retrieved November 20, 2007 from http://www.prochange.com/ttm.

Prochaska, J. J., \& Velicer, W.F. (1997). Behavior change: The Transtheoretical Model of health behavior change. American Journal of Health Promotion, 12, 38-48. 
Prochaska, J.J., Velicer, W.F., Nigg, C.R., \& Prochaska, J.O. (2008). Methods of quantifying change in multiple risk factor interventions. Preventive Medicine, 46, 260-265.

Prochaska, J.M. (2007). The transtheoretical model applied to the community and the workplace. Journal of Health Psychology, 12, 198-200.

Prochaska, J.O., \& Marcus, B.H. (1994). The transtheoretical model: Applications to exercise. In R.K. Dishman (Ed.), Advances in exercise adherence (pp. 161-180). Champaign, IL: Human Kinetics.

Prochaska, J.O., Velicer, W.F., Redding, C., Rossi, J.S., Goldstein, M., DePue, J., Greene, G.W., Rossi, S., Sun, X., Fava, J.L., Laforge, R., Rakowski, W., \& Plummer, B.A. (2005). Stage-based expert systems to guide a population of primary care patients to quit smoking, eat healthier, prevent skin cancer, and receive regular mammograms. Preventive Medicine, 41, 401-416.

Reilly, T. \& Peiser, B. (2006). Seasonal variations in health-related physical activity. Sports Medicine, 36, 473-485.

Ross, M. (2008). Spotlight on Healthy Eating Every Day: Healthy Eating Every Day (HEED) online program. Active Living Every Day. Retrieved October 23, 2008 from http://www.activeliving.info/ViewArticle.cfm?ID=310\&SECTION=3.

Sallis, J.F. \& Owen, N. (1999). Physical activity and behavioral medicine. Thousand Oaks, CA: Sage Publications.

Sevick, M.A., Dunn, A.L., Morrow, M.S., Marcus, B.H., Chen, G.J., \& Blair, S.N. (2000). Cost effectiveness of lifestyle and structured exercise interventions in sedentary adults: Results of Project Active. American Journal of Preventive 
Medicine, 19, 1-8.

Spittaels, H., Bourdeaudhuij, I., \& Vandelanotte, C. (2007). Evaluation of a websitedelivered computer-tailored intervention for increasing physical activity in the general population. Preventive Medicine, 44, 209-217.

Strandberg, T.E., Tilvis, R.S., Pitkala, K.H., \& Miettinen, T.A. (2006). Cholesterol and glucose metabolism and recurrent cardiovascular events among the elderly: A prospective study [Electronic version]. Journal of American College Cardiology, $48,708-714$.

Strauss, A., \& Corbin, J. (1990). Basics of qualitative research: Grounded theory procedures and techniques. Newbury Park, CA: Sage Publications.

Stellefson, M., Chaney, B., \& Chaney, D. (2008). The digital divide in health education: Myth or reality? American Journal of Health Education, 39, 106-112.

Strecker, L.E. (2008). Online resources for promoting a healthy and active lifestyle. Update Plus: Magazine of the American Alliance for Health, Physical Education, Recreation and Dance, March/April, 6-8.

Sykes, H., \& McPhail, D. (2008). Unbearable lessons: Contesting fat phobia in physical education. Sociology of Sport Journal, 25, 66-96.

Tod, A.M. (2004). Overweight and obesity: Helping clients to take action. British Journal of Community Nursing, 9, 59-66.

Tryon, W.W., Pinto, L.P., \& Morrison, D.F. (1991). Reliability assessment of pedometer activity measurements. Journal of Psychopathology and Behavioral Assessment, 13, 27-43.

Tudor-Locke, C., \& Bassett, D.R. (2004). How many steps/day are enough? 
Preliminary pedometer indices for public health. Sports Medicine, 34, 1-8.

Tudor-Locke, C., Burkett, L., Reis, J.P., Ainsworth, B.E., Macera, C.A., \& Wilson, D.K. (2005). How many days of pedometer monitoring predict weekly physical activity in adults? Preventive Medicine, 40, 293-298.

Tung, W.C., \& Gillett, P.A. (2004). Stages of change for physical activity among family caregivers. Journal of Advanced Nursing, 49, 513-521.

Vandelanotte, C., Bourdeaudhuij, I., Sallis, J.F., Spittaels, H., \& Brug, J. (2005). Efficacy of sequential or simultaneous interactive computer-tailored interventions for increasing physical activity and decreasing fat intake. Annals of Behavioral Medicine, 29, 138-146.

West Virginia Department of Health and Human Resources. (2005). Number and percent distribution of leading causes of death by years of potential life lost before age 75 and actual deaths: West Virginia residents, 2004 and 2005. Retrieved October 8, 2007 from http://www.wvdhhr.org/bph/oehp/hsc/pubs/vital05/vs 32.htm.

Wilcox, S., Dowda, M., Griffin, S.F., Rheaume, C., Ory, M.G., Leviton, L., King, A.C., Dunn, A., Buchner, D.M., Bazzarre, T., Estabrooks, P.A., Cabpbell-Yoytal, K., Bartlett-Prescott, J., Dowdy, D., Castro, C..M., Carpenter, R.A., Dzewaltowski, D.A., \& Mockenhaupt, R. (2006). Results of the first year of Active for Life: Translation of 2 evidence-based physical activity programs for older adults into community settings. American Journal of Public Health, 96, 1201-1209. 
Table 1

High-Achievers' Averages $\mathrm{O}_{1}$ through $\mathrm{O}_{4}$

\begin{tabular}{llll}
\hline Process Measures & Product Results & Themes (Frequencies) & Themes (Key Words) \\
\hline Module Completion 20 & BMI-No change or improved & Time-2.33 & Made time for activity \\
Number of Minutes 277.99 & Steps-Remained Low Active & Accountability-1.33 & Praised accountability \\
Non-Tool Pages Visited 66.67 & HDL-Improved 47.66 to 55.00 & Facilitation-3.00 & Praised facilitator \\
& LDL-Improved 144.00-94.00 & Ease of Use-8.33 & ALED Online user-friendly \\
& SOC-Improved to Action or & Rationalization-8.0 & Health benefits \\
& remained Maintenance & Thoughts-7.0 & Positive \\
& & Behavior-4.66 & Listed activities \\
\hline
\end{tabular}


Table 2

Mid-Achievers' Averages $\mathrm{O}_{1}$ through $\mathrm{O}_{3}$

\begin{tabular}{llll}
\hline Process Measures & Product Results & Themes (Frequencies) & Themes (Key Words) \\
\hline Module Completion 10.5 & BMI-No change & Time-2.5 & Time constraints \\
Number of Minutes 306.78 & Steps-Remained Low Active & Accountability-1.0 & Wanted accountability \\
Non-Tool Pages Visited 43.5 & HDL-Improved 71.5 to 82.5 & Facilitation-2.5 & Comfort with facilitator \\
& LDL-Improved 108.5 to 105.5 & Ease of Use-4.0 & Easy to use \\
& SOC-Improved & Rationalization-9.5 & Health benefits of activity \\
& & Thoughts-3.5 & Positive
\end{tabular}


Table 3

Drop-Outs' Averages $O_{1}$

\begin{tabular}{llll}
\hline Process Measures & Product Results & Themes (Frequencies) & Themes (Key Words) \\
\hline Module Completion 4.33 & BMI-36.4 & Time-3.0 & Didn't make time \\
Number of Minutes 135.65 & Steps-Remained Low Active & Accountability-2.33 & Wanted more from ALED Online \\
Non-Tool Pages Visited 30.33 & HDL-54.00 & Facilitation-2.33 & Wasn't what was expected \\
& LDL-112.00 & Ease of Use-4.33 & Internet access issues \\
& SOC-Ranged from Contemplation & Rationalization-4.33 & Rationalized health issues \\
& to Action & Thoughts-1.33 & Few thoughts about PA \\
& & Behavior-0 & No change
\end{tabular}


Figure 1. Research Design

Figures

\begin{tabular}{|lllllllll|}
\hline & \multicolumn{1}{c}{ Week 1 } & Week7 & Week 14 & \multicolumn{2}{l|}{ Week 21 } \\
Experimental Group & $\mathrm{R}$ & $\mathrm{O}_{1}$ & $\mathrm{X}_{1}$ & $\mathrm{O}_{2}$ & $\mathrm{X}_{2}$ & $\mathrm{O}_{3}$ & $\mathrm{C}$ & $\mathrm{O}_{4}$ \\
\hline
\end{tabular}

Figure 1. Research Design

Figure Captions

$\mathrm{R}=$ Recruitment

$\mathrm{O}_{1}=$ Observation (Lipid blood analysis, BMI, SOC, Step Count)

$\mathrm{X}_{1}=$ Begin Intervention

$\mathrm{O}_{2}=$ Observation (Lipid blood analysis, BMI, SOC, Step Count)

$\mathrm{X}_{2}=$ End Intervention

$\mathrm{O}_{3}=$ Observation (Lipid blood analysis, BMI, SOC, Step Count, Interviews and Document

Analysis)

$\mathrm{C}=$ Control

$\mathrm{O}_{4}=$ Observation (Lipid blood analysis, BMI, SOC, Step Count, Interviews and Document Analysis) 
Figure 2. Number of Participants with Step Count Data

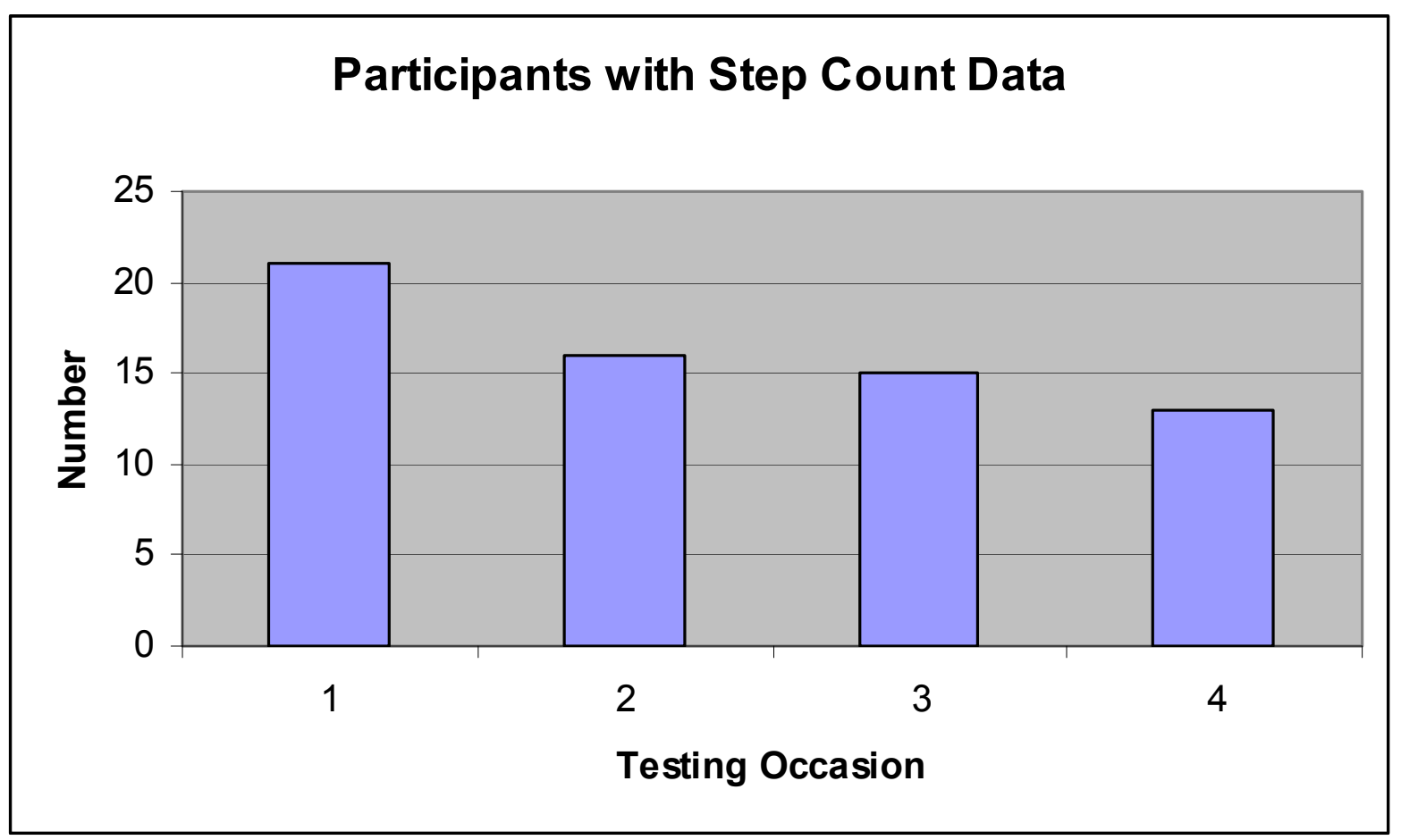


Figure 3. HDL Cholesterol for Research Adherents $\mathrm{O}_{1}$ through $\mathrm{O}_{4}$

\section{Estimated Marginal Means of HDL}

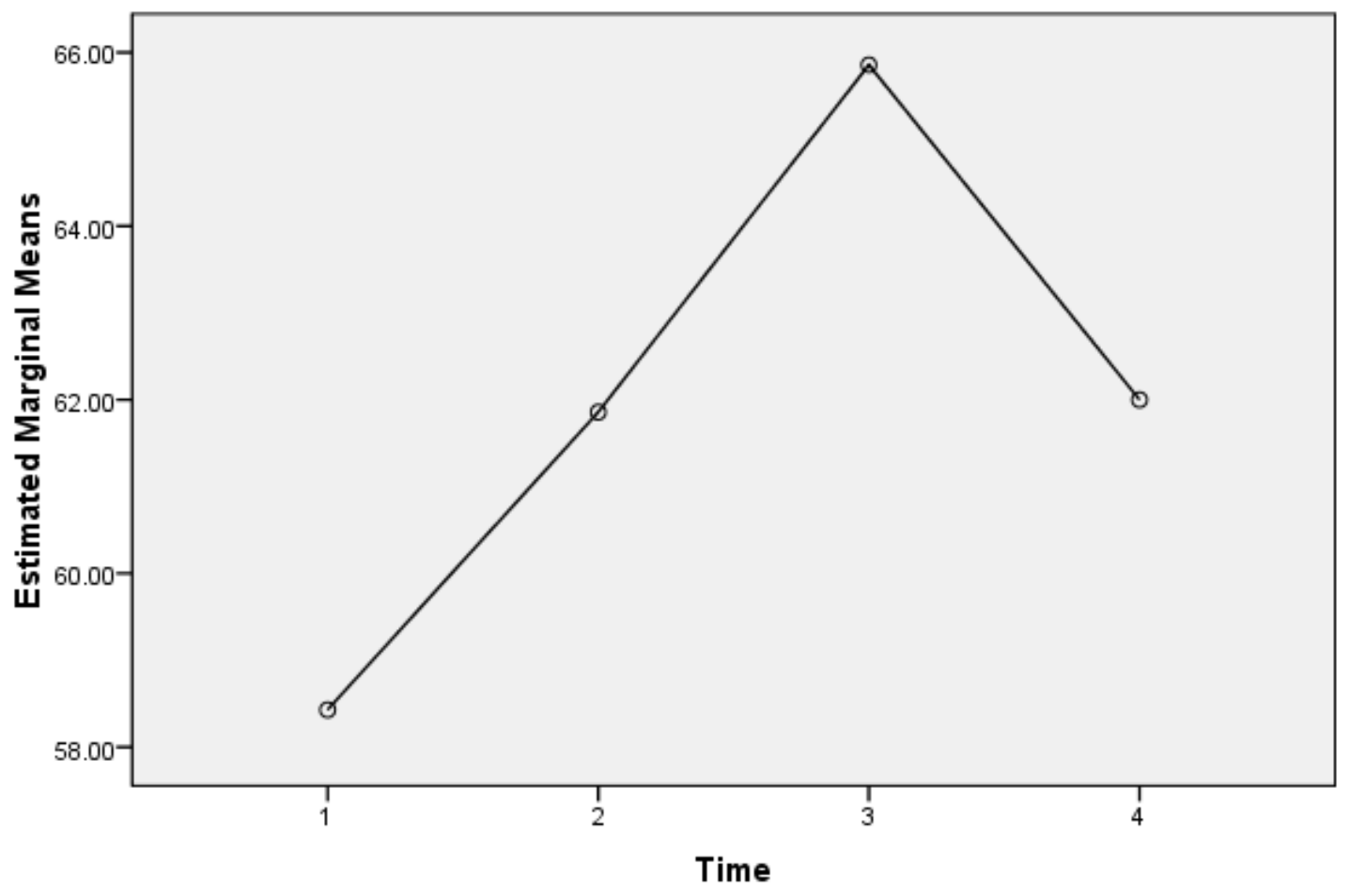


Figure 4. LDL Cholesterol for Research Adherents $\mathrm{O}_{1}$ through $\mathrm{O}_{4}$

\section{Estimated Marginal Means of LDL}

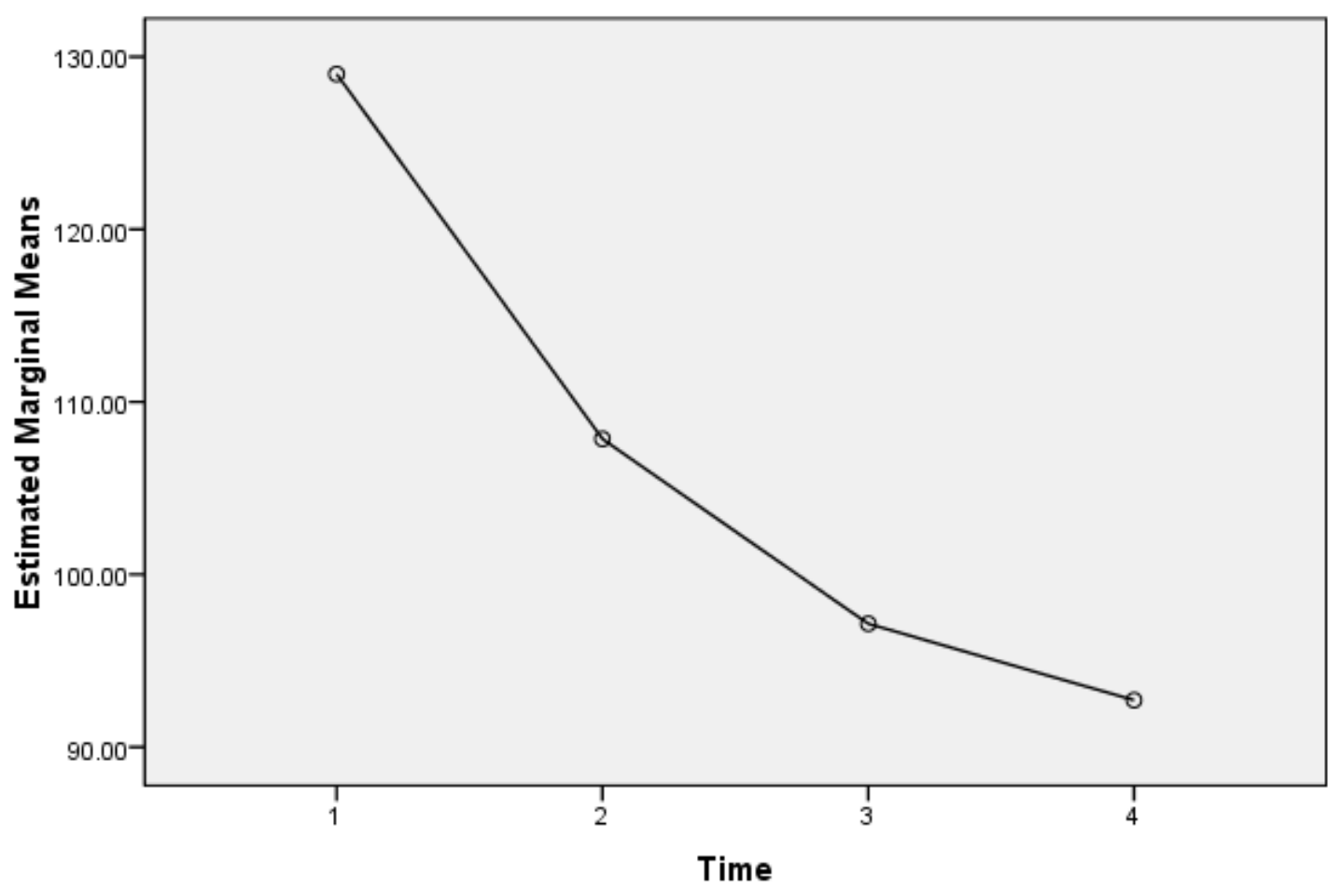


Figure 5. SOC for Research Adherents $\mathrm{O}_{1}$ through $\mathrm{O}_{4}$

\section{Estimated Marginal Means of SOC}

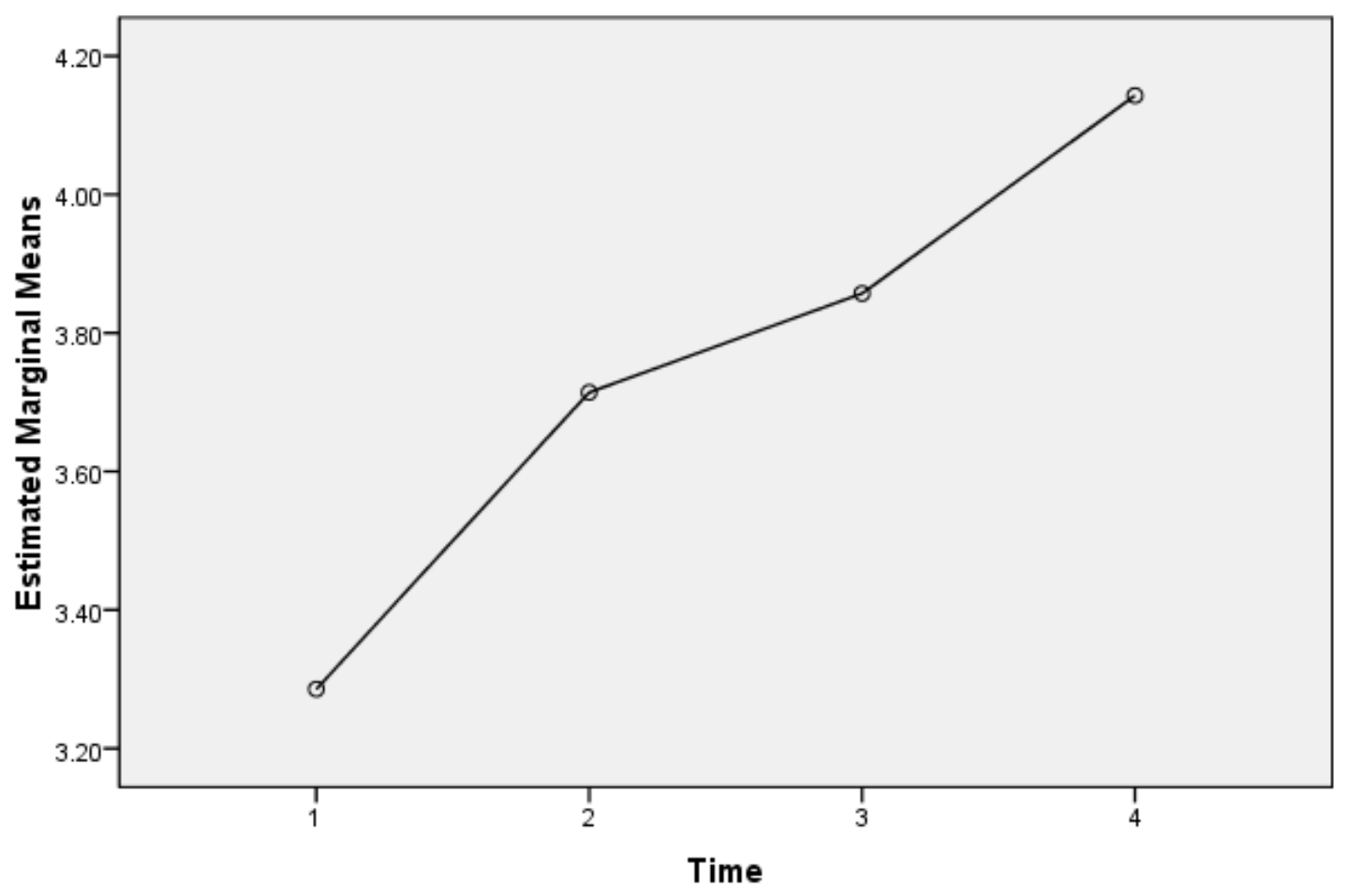


Appendices

Appendix A Physical Activity Readiness Questionnaire (PAR-Q)

Physical Actinty Readhes: Questionnake - PAR-Q (revised 1994)

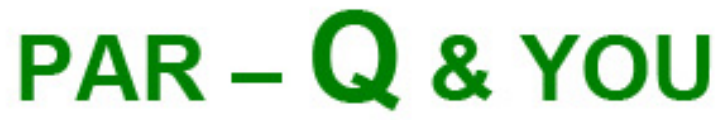

(A Questionnaire for People Aged 15 to 69)

Regular physical activity is fun and healthy, and increasingly more people are starting to become more active every day. Being more active is very safe for most people. However, some people should check with their doctor before they start becoming much more physically active.

If you are planning to become much more physically active than you are now, start by answering the seven questions in the box below. If you are between the ages of 15 and 69 , the PAR-Q will tell you if you should check with your doctor before you start. If you are over 69 years of age, and you are not used to being very active, check with your doctor.

Common sense is your best guide when you answer these questions. Please read the questions carefully and answer each one honestly. check YES or NO.

\begin{tabular}{|ccl}
\hline YES & NO & \\
$\square$ & $\square$ & 1. Has your doctor ever said that you have a heart condition and that you should only do physical activity \\
$\square$ & $\square$ & 2. Do you feel pain in your chest when you do physical activity? \\
$\square$ & $\square$ & 3. In the past month, have you had chest pain when you were not doing physical activity? \\
$\square$ & $\square$ & 4. Do you lose your balance because of dizziness or do you ever lose consciousness? \\
$\square$ & $\square$ & 5. Do you have a bone or joint problem that could be made worse by a change in your physical activity? \\
$\square$ & $\square$ & 6. Is your doctor currently prescribing drugs (for example, water pills) for your blood pressure or heart condition? \\
$\square$ & $\square$ & 7. Do you know of anv other reason why you should not do physical activity?
\end{tabular}

If

\section{YES to one or more questions}

you answered Tak with your doctor by phone or In person BEFORE you start becoming much more phys You may be abie to do any activity you want - as long as you start slowly and bulld up gradually. Or, you may need to restrict your activites to those which are safe for you. Talk with your doctor about the kinds of activites you wiah bo participate in and follow his/her advice.

- Find out which community programs are sate and heiptul for you.

NO to all queStions
If you answered NO honesty to al PAR-Q questions, you can be ressonably
sure that you can:
- start becoming much more physkcaly sctive - begin slowty and bulid
up gradually. This is the satest and easiest way to go.
- take part in a fithess appralsal - this is an excelient way bo detemine
your bask thess so that you can plan the best way for you to live
actlvely.

DELAY BECOMING MUCH MORE ACTIVE:
- If you are not feelling wel because of temporary liness such
as a cold or a fever - wath untll you feel better; or
- If you are or may be pregnant - taik to your doctor before you
start becoming more active.
actively.

Pleace note: If your health changes so that you then anewer YES to any of the above questlons, tell your finess or health protessional. Ask whether you ahould change your physkal activity plan.

Intormed Use of the PAR-Q: The Cansdian Soclety for Exerclae Fhysiology, Health Cansda, and treir apents assume no lability for persons who undertake physical activity, and If In doutt ather completing tils questonnaire, consult your doctor prior to physical activity.

\section{You are encouraged to copy the PAR-Q but only if you use the entire form}

NOTE: If the PAP-Q is being given to a person before he or she pancipotes in a physical activty program or a finess appralsal, mis section may be used for iegal or adiministrative purposes.

I have read, understood and completed this questionnaire. Any questions I had were answered to my full satisfaction.

NAME

SIGNATURE

SIGNATURE OF PARENT

or GUARDIAN (for particlasnts under the age of malority)

๑ Canadian Society for Exerclse Physloiogy

Soclete. canadienne de physiologie de lexercice
DATE

WITNESS

continued on other side...

Supported by:

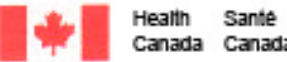




\section{Appendix B Stage of Change Decision Tree}

Name:

Date:

HO\#2-1

\section{Readiness to Change}

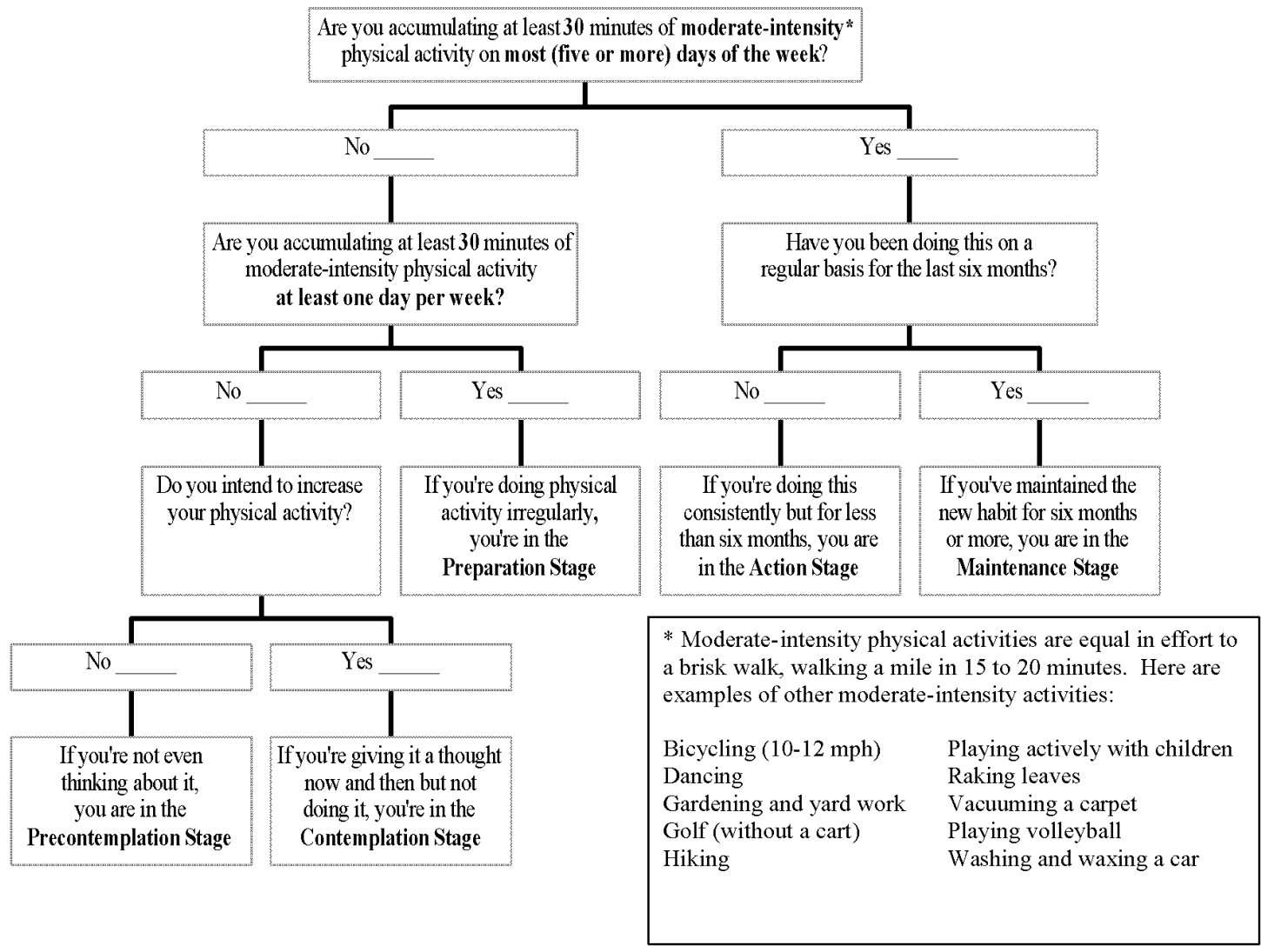


Appendix C Demographic Information Sheet

\section{WhestVrirginiaUniversity. \\ ACTIVE LIVING}

\section{Active Living Every Day Registration Form}

Name:

Mailing Address:

Phone Number:

May we call you? Please Circle. Yes or No

What time of day and day of the week may we call?

What is your email address?

What is your gender? Please Circle. Male or Female

What is your race/ethnicity?

What is your current age?

What is your height?

What is your weight?

The information you provided will be used for the purposes of a dissertation research study. This project has been reviewed by West Virginia University's Institutional Review Board for the Protection of Human Subjects and marked approved. If you have any questions about your participation in the study, you may contact Amy Sidwell at 304-290-7213 or Dr. Sean Bulger at 304-293-3295 ext. 5209. 
Appendix D Semi-Structured Interview

Interview \#_ Interviewer
Date:

Time:

Interview Type: Phone or Email

Interviewee's Pseudonym: Numeric Identifier:

Interview script:

Hello . This is Amy Sidwell, and I'm calling to talk about your experiences with the Active Living Every Day program. Do you have a few minutes to share your thoughts with me? This interview should take approximately 20 minutes. You may refuse to answer any questions you are asked.

Question 1: Did this program meet your expectations?

Prompt: What were the strengths of the program?

Prompt: What were the weaknesses of the program?

Question 2: Did you have any barriers to participating in the program?

Prompt: Did you have problems incorporating more physical activity into your life?

Prompt: Did you have problems with your computer, email, internet, or the ALED website?

Question 3: What did you think of the website?

Prompt: Was the website easy or difficult to use?

Question 4: What did you think of the book?

Prompt: Did you prefer using the website or the book?

Question 5: Did you feel that this program changed your behaviors or thoughts about physical activity?

Question 6: Is there a suggestion you could make for improving the program?

Question 7: Is there anything else you would like to share that I haven't asked you about? 
Appendix E Control Condition Questionnaire

Name:

Date:

Has your physical activity changed in the past seven weeks?

Yes or No (please circle)

Has your physical activity increased or decreased in the past seven weeks?

Increased or Decreased (please circle)

If your physical activity has increased, describe what you are doing now that you weren't doing seven weeks ago.

Are you eating any differently than you were seven weeks ago? Yes or No (please circle)

If you are eating differently than you were seven weeks ago, describe how you are eating now compared to how you were eating seven weeks ago. 


\section{CURRICULUM VITAE}

Amy M. Sidwell, Ph.D., CHES

(304) 598-0274

amrogers3@verizon.net

\section{EDUCATION}

August 2006-May 2009: Kinesiology (Physical Education Teacher Education) Doctoral Program, West Virginia University, College of Physical Activity and Sport Sciences (3.84 grade point average/4.0 scale for all graduate work). Successfully defended dissertation March 2009. Doctoral degree will be conferred May 2009. Completed all coursework Spring 2008. Completed comprehensive exams and defended dissertation prospectus Summer 2008. Cognates: Educational Psychology and Statistics/Research Design. Dissertation topic: "The Effects of Active Living Every Day Online on Physical Activity."

December 2000: Masters of Science Community Health Education, West Virginia University, School of Medicine (3.72 grade point average/4.0 scale).

May 2000: Graduate Certificate, Health Care Administration, West Virginia University.

May 1998: Bachelor of Science Health and Physical Education, Edinboro University of Pennsylvania (3.79/4.0 scale). Minor areas of study: Fitness Management and Art History.

May 1998: Completion of Edinboro University of Pennsylvania Honors Program. Received Honors Scholarship to attend Oxford University (Exeter College, England) to study English Literature and Life. Completed Independent Studies in Adaptive Physical Education.

\section{WORK EXPERIENCE}

January 20009-present: Adjunct Professor, Canisius College, Graduate Department of Physical Education. Responsibilities include teaching two sections of Master's level, graduate courses in Adapted Physical Education to physical education and health education teachers. Courses are delivered entirely online.

August 2007-August 2008: Visiting Lecturer, West Virginia University, College of Physical Activity and Sport Sciences. Responsibilities included teaching undergraduate and graduate courses in Adapted Physical Education, coordinating the "Friday Program" (adapted physical education program for children with disabilities enrolled in eleven local schools), supervising Graduate Assistants, supervising student teachers, advising undergraduate students, program evaluation, and providing service.

August 2006-May 2007: Graduate Assistant, West Virginia University, School of Physical Education (College of Physical Activity and Sport Sciences). Responsibilities included advising 505 undergraduate students majoring in Physical Education/Health Education, Pre-Athletic Coaching Education, and PreSports Management. Accomplishments included creating advising workshops, developing a job resource center, providing sessions during New Student Orientation, and recruiting prospective students during High School Visitation Days.

May 2004-February 2006: Community Health/Community Wellness Coordinator, Monongalia Health System, Marketing Department. Responsibilities included managing staff members for implementation of community health screenings, selling wellness services to corporate clients, collaborating with community partners to improve community health status, and serving as a regional community health resource. Major accomplishments included directing screenings for approximately 6000 patients which generated revenue totaling nearly $\$ 180,000$, directing a cancer awareness and detection project, supervising on-call staff, creating an innovative quarterly Community Services Report, creating a standardized Funding Request process for the Health System, providing blood pressure screenings during monthly community walking program, and streamlining technical processes for patient registration. 
February 2004-December 2004: Owner, Acadia Consulting and Training, LLC. Responsibilities included business development, marketing, strategic planning, and grant writing services in order to serve businesses, communities and schools.

November 2000-February 2004: Community Development Specialist and Evaluation Team Liaison, West Virginia Prevention Resource Center, Marshall University Research Corporation. Responsibilities included mobilizing communities in Northern West Virginia to provide prevention education programs, training professionals to implement programs, promoting alternative activities to drug use, grant writing and serving as a liaison to the Institutional Review Board for my colleagues.

July 2000-November 2000: Community Development Specialist for Substance Abuse Prevention, Appalachian Community Health Center. Responsibilities included community mobilization throughout Central West Virginia, providing prevention education programs, promoting alternative activities to drug use, and grant writing.

January 1999-May 2000: Coordinator/Graduate Assistant, Vision 2000 Students Together in Athletics and Recreation (STAR) Program. Responsibilities included promoting a cardiovascular health promotion program to schools, businesses, and communities by providing lessons in physical activity, nutrition, and tobacco use prevention to approximately 1400 elementary school students. Major accomplishments included working with a volunteer task force comprised of community leaders, leveraging funding and inkind support, and creating media opportunities for the program.

1992-1998: Director of Weekend Programs, Assistant Ski School Director, Ski Instructor, Mountain View at Edinboro, Edinboro, PA. Responsibilities included training and supervising ski instructors, assisting the director, managing all weekend programs, and instructing skiers.

January 1998-March 1998: Student Teacher, Harding Elementary, Erie, PA. Instructed Grades K-6 Physical Education and Grade 7 Health Education.

March 1998-May 1998: Student Teacher, Wilson Middle School, Erie, PA. Instructed Grades 6-8 Physical Education and Grades 7 and 8 Health Education.

\section{TEACHING}

Spring 2009 Canisius College: PEG 530 ONL and PEG 530 WEB Physical Education for the Exceptional Individual. Currently teaching two sections of an online/web-delivered class to master's level graduate students. The purpose of the course is to teach physical educators to design inclusive physical education programs in schools. Assignments include article reviews, case studies, interviews, and program designs which culminate in a comprehensive course project.

Summer 2008 West Virginia University: PET 681 Motor Development for Special Populations. Taught an online class for students pursuing a Master's degree in Physical Education. The course was designed to examine the motor development patterns of various special population groups, while focusing on the physical educator's role with the developmental process. Current developmental research was shared with the class. PET 681 was delivered entirely online, with posted readings, discussion board posting, quizzes, and scenario responses serving as the evaluation component of the course.

Summer 2008 West Virginia University: PET 101 Games in American Culture. Served as a co-instructor in West Virginia University's College of Physical Activity and Sport Sciences. This course examined the social history of a variety of American games, their development, and how games have impacted American society.

Spring 2008 and Fall 2007 West Virginia University: PET 477 Special Physical Education Practicum. Taught adapted physical education practicum within Physical Education Teacher Education. Course was taught in a seminar/lecture format, with a clinical lab experience one day per week. Lecture portion of the class included lesson planning, reflection and collaboration. Students were expected to develop, implement, and assess lessons based on the unique needs of their learners. 
Spring 2008 and Fall 2007 West Virginia University: PET 276 Special Physical Education. Taught introduction to adapted physical education course within Physical Education Teacher Education. Course was taught in a two-pronged format, with lecture and clinical lab experience. Lecture portion of class included written assignments and weekly quizzes on topics such as common impairments, etiology, legislation, and special education topics. Lab experience included working with children with disabilities one day per week.

Fall 2007 West Virginia University: Supervised two student teachers in elementary school physical education settings. One placement occurred in a rural school, and the other placement occurred in a multicultural setting. Provided feedback on teaching, lesson planning, and unit planning.

Summer 2007 and Summer 2008 West Virginia University: PET 483/485 Issues/Supervision in Physical Education. Served as a co-instructor in West Virginia University's School of Physical Education. Provided tools necessary for pre-service physical educators to evaluate and document instructional effectiveness.

Spring 2007 West Virginia University: PE 160 Beginning Tennis. Supervised two pre-service teachers instruct Beginning Tennis in the Basic Instruction Program at West Virginia University. Provided feedback on teaching, lesson planning, and unit planning.

Spring 2007 West Virginia University: Supervised one student teacher in a rural, elementary physical education setting. Provided feedback on teaching, lesson planning and unit planning.

\section{SCHOLARLY PRESENTATIONS}

Sidwell, A.M. 2009. "Memories of Physical Education." American Alliance for Health, Physical Education, Recreation and Dance (AAHPERD) National Convention: Tampa, FL.

Sidwell, A.M. 2009. "The Future of Physical Education? Distance Learning in Physical Activity." National Association for Kinesiology and Physical Education in Higher Education (NAKPEHE) Conference: Sarasota, FL.

Sidwell, A.M. 2008. "Finding Support for Health Education and Physical Education Programs." West Virginia Association for Health, Physical Education, Recreation and Dance Convention: Canaan Valley, WV.

Sidwell, A.M. 2008. "Using SWOT Analysis for Adapted Physical Education Program Evaluation." National Association for Kinesiology and Physical Education in Higher Education (NAKPEHE) Conference: Albuquerque, NM.

Bulger, S.M. \& Sidwell, A.M. 2008. "Student Learning and Capstone Courses: Assessing Reflection, Integration, and Transition." National Association for Kinesiology and Physical Education in Higher Education (NAKPEHE) Conference: Albuquerque, NM.

Sidwell, A.M. 2007. "The Argument Against Wellness." Historic Traditions \& Future Directions in Research on Teaching \& Teacher Education in Physical Education: Pittsburgh, PA.

Sager, J., Sidwell, A., Jahn, J., Choi, Y., Langley, J., Metcalf, A. \& Towner, B. (2007). "Student Teachers' Experiences, Attitudes and Beliefs in Utilizing the Sport Education Curricular Model." Historic Traditions \& Future Directions in Research on Teaching \& Teacher Education in Physical Education: Pittsburgh, PA.

Sidwell, A.M. \& Bulger, S.M. 2007. "Facilitating the Senior Year Experience in Physical Education Teacher Education.” National Student Teacher Supervision Conference: Slippery Rock, PA. 
Sidwell, A.M. \& Jahn, J.A. 2007. "A Multidisciplinary Approach to Implementing Physical Activity Guidelines." National Association for Kinesiology and Physical Education in Higher Education

(NAKPEHE) Conference: Clearwater, FL.

Sidwell, A. \& Linger, A. 2003. "Fetal Alcohol Syndrome: What School Staff and Parents Need to Know." Share the Vision Conference: Charleston, WV.

\section{SCHOLARSHIP}

Rogers-Sidwell, A.M. \& Thomas, C. (2009). Introduction to philosophic issues. In L.D. Housner, M.W. Metzler, P.G. Schempp, \& T.J. Templin (Ed). Historic Traditions and Future Directions of Research on Teaching and Teacher Education in Physical Education. Morgantown, WV.

DiGiacinto, K. \& Rogers-Sidwell, A.M. (2009). Introduction to youth sport, physical activity, public health, and social change. In L.D. Housner, M.W. Metzler, P.G. Schempp, \& T.J. Templin (Ed). Historic Traditions and Future Directions of Research on Teaching and Teacher Education in Physical Education. Morgantown, WV.

Sidwell, A.M., Wiegand, R.L., Sager, J.W., \& Pritchard, T. (2009). Changes in pre-service physical educators' planning behavior. Manuscript in preparation.

Sidwell, A.M. \& Walls, R.T. (2009). Memories of physical education. Manuscript in preparation.

Sidwell, A.M. (2009). The argument against wellness. Manuscript in preparation.

Rogers, A.M. (2000). Subjective Norms, Attitudes, Body Mass Indices, and Self Esteem as Influences on Women's Body Image Behavior. Master's thesis, West Virginia University, Morgantown, West Virginia.

\section{RESEARCH SKILLS}

Graduate coursework: Educational Research Methods, Statistics I, Statistics II, Multivariate Statistics, Program Evaluation, Qualitative Research Methods, and Advanced Qualitative Research Methods. Institutional Review Board: Collaborative Institutional Training Initiative (CITI) for Social and Behavioral Investigators. Submitted IRB protocols as a member of research teams. Served as IRB liaison for colleagues.

Statistics: Use SPSS software extensively to generate descriptive and multivariate statistics. Familiarity with SAS output.

Mixed method research: Prepared dissertation using quantitative-qualitative mixed methods design. Used qualitative design to generate themes, and used multivariate statistics to examine group differences. Conducted individual interviews and focus groups. Used document analysis in a number of research projects.

Program Evaluation: Completed two comprehensive program evaluations. The findings of the first were presented at a national higher education in kinesiology conference. The findings of the second will be presented at a national physical education teacher education conference in October 2009.

\section{LICENSURE}

April 2000: Obtained Certified Health Education Specialist Credentials

May 1998: Pennsylvania Teacher's Certificate: Health Education and Physical Education, Grades

Kindergarten-12

\section{CERTIFICATIONS}

March 2008: Certified as a Director and Facilitator for Active Living Every Day. Active Living Every Day is a course developed by the Cooper Institute and facilitated by Human Kinetics through Active Living Partners. 
February 2008: Certified in Adult, Infant, and Child CPR, and Automated External Defibrillation by American Red Cross

December 2006: Certified in Community First Aid and Safety, Adult, Infant, and Child CPR, and Automated External Defibrillation by American Red Cross

October 2006: Certified as a Physical Best Health-Fitness Specialist by the National Association for Sport and Physical Education (NASPE)

\section{GRANT AND FUNDING ACTIVITY}

February 2009: West Virginia on the Move, Schools on the Move Grant Program. Grant leader on behalf of Morgantown Learning Academy. Requested \$5000. Not funded.

January 2009: West Virginia University Dissertation Fellowship, West Virginia University Office of Graduate Education. Awarded \$6000.

July 2008: "The Effects of Active Living Every Day Online on Physical Activity." West Virginia University, College of Physical Activity and Sports Sciences Internal Grant Program. Awarded \$1750.

June 2008: Phi Kappa Phi National Honor Society, “Love of Learning Award.” Applied for \$500 to support dissertation. Not funded.

April 2008: Active Living Partners, Active Living Every Day. Site License Fee waived. Awarded $\$ 1000$ in-kind funding.

CONTINUING EDUCATION

February-March 2008: Completed Active Living Every Day Director and Facilitator training.

May 2007: Technology training in physical education. Introduction to Pocket PC, heart rate monitors, PE Manager, and Tri-FIT software.

October 2003: Certified as a trainer for "Family-Centered Practice," West Virginia Department of Health and Human Services. Provided "Family-Centered Practice" training in Ritchie County, West Virginia.

August 2003: Received Trainer-of-Trainer Credentials for "Fetal Alcohol Syndrome: What School Staff and Parents Need to Know," Educational Development Center, Centers for Disease Control and Prevention. Provided workshop at Share the Vision conference (Charleston, WV) in 2003 on this topic.

November 2002: Received Trainer-of-Trainer Credentials for "Project Toward No Drug Abuse," Center for Substance Abuse Prevention.

June 2002: Trained as a presenter of "Keep a Clear Mind” Project, Center for Substance Abuse Prevention. Presented the lessons to fourth grade students in Monongalia County, West Virginia after-school programs.

October 2001: Trained as a presenter in "Natural Helpers" peer helper program, and implemented the program in schools and after-school programs throughout West Virginia.

September 2001: Attended training and organized a training in "Communities of Excellence in Tobacco Control," American Cancer Society. Implemented the training in two West Virginia counties. Served as a resource in "Communities of Excellence" for Harrison/Marion Bi-County Tobacco Prevention Coalition.

July 2001 and June 2002: Completion of Synar Tobacco Compliance Inspection Training, West Virginia Prevention Resource Center. Worked with West Virginia State Police to complete inspection of retailers in seven West Virginia counties to ensure that retailers were not selling tobacco products to minors. 
March 2001: Certified as a presenter of "True Colors," and provided numerous workshops throughout North Central West Virginia to schools, businesses, and wellness organizations.

February 2001: Attended "Prevention Generalist Education," Centers for the Application of Prevention Technology

December 2000: Completed workshop entitled "Outcome Evaluation," South Charleston IMPACT

October 2000: Completed "Teens Against Tobacco Use Adult Training Program," American Lung Association. Implemented the training in one West Virginia County.

August 2000: Certified as a presenter in "Beginning Alcohol and Addictions Basic Education Studies," BABES World. Provided presentations to day care centers and Head Start Centers throughout North Central West Virginia. Assisted Rape and Domestic Violence Information Center secure a grant for BABES training.

\section{SERVICE}

Spring 2008: Served on search committee for Clinical Assistant Professor within the College of Physical Activity and Sport Sciences at West Virginia University.

January 2008-April 2008: Reviewed manuscripts and wrote two chapter introductions for publication of proceedings of Historic Traditions \& Future Directions in Research on Teaching \& Teacher Education in Physical Education conference. Manuscripts and chapter themes included "Philosophic Issues" and "Youth Sport, Physical Activity, Public Health \& Social Change.”

January 2008: Presented staff development workshop to Brooke County Health and Physical Education teachers entitled "Soliciting Support for Health and Physical Education Programming."

January 2005-September 2008: Marketing Committee Member, National Commission on Health Education Credentialing. Responsibilities included providing representation to a national credentialing body in order to promote the Certified Health Education Specialist credential.

October 2006-December 2006: Prepared evaluation project in conjunction with National Association for Sport and Physical Education (NASPE) in order to assess "Physical Best" program. Responsibilities included interviewing physical education teachers and preparing abstracts of the interviews in preparation of manuscript.

January 2006-May 2006: Reviewer, Citizens Review Committee, United Way of Monongalia and Preston Counties. Responsibilities included making funding recommendations to United Way after evaluating local non-profit organizations.

January 1999-February 2006: Task Force Member, Vision 2020 Health and Wellness Committee, Morgantown Area Chamber of Commerce. Responsibilities included meeting with local health and wellness professionals, local residents, and Chamber of Commerce in order to address health needs and resources in our community.

November 2000-January 2002: Member, Harrison/Marion Bi-County Tobacco Prevention Coalition. Provided grant writing assistance, technical support on clean indoor air ordinances, and health fair organizational assistance.

November 2000-August 2003: Member, Planned Approach to Community Health (PATCH) of Monongalia County, WV. Provided technical assistance to PATCH in order to plan health promotion activities for the community. 


\begin{abstract}
ADDITIONAL EXPERIENCE
May 2006-present: Interpreter, Fallingwater, Western Pennsylvania Conservancy, Mill Run, PA. Work in the Department of Education and Interpretation as a museum tour guide. Provide presentations on Fallingwater, its architectural importance, and its significance in Frank Lloyd Wright's career.

May 1996-August 1996: Camp Counselor and Kayaking Instructor, Camp Danbee, Hinsdale, MA. Major responsibilities included providing oversight for fourth and fifth grade girls, serving as a "beach master" (head lifeguard) at the lakefront, and teaching beginning kayaking skills.
\end{abstract}

August 1996: Camp Counselor, Belvoir Terrace, Lenox, MA. Served as a camp counselor for children and adults with Williams Syndrome. At that time, there were only 60 people in the United States diagnosed with Williams Syndrome. Belvoir Terrace's Williams Syndrome Camp was profiled in a television report by CBS's 60 Minutes.

May 1997-January 1998: Lifeguard, Dr. Gertrude A. Barber Center, Erie, PA. Worked as a lifeguard at a school and residential facility for children and adults with disabilities.

PROFESSIONAL AFFILIATIONS

American Alliance for Health, Physical Education, Recreation and Dance (AAHPERD): Affiliations include American Association for Health Education (AAHE), National Association for Sport and Physical Education (NASPE), Midwest District, and Research Consortium

National Association for Kinesiology and Physical Education in Higher Education (NAKPEHE): Joined as Graduate Student Member 2006

Phi Epsilon Kappa, Physical Education Fraternity: Inducted 1996 and re-inducted December 2006

\title{
HONORS
}

2009 West Virginia University Dissertation Fellow

2008 Phi Kappa Phi National Honor Society

2007-2008 Outstanding Graduate Student Award, West Virginia University

2007 Dr. Patricia K. Fehl Graduate Student Scholarship, West Virginia University

1998 Alpha Chi, National College Honors Scholarship Society (Inducted)

1996-1997 Who's Who Among Students in American Universities and Colleges (Elected)

1997 Oxford University, England Study Abroad Scholarship, Edinboro University of PA

1992 Dollars for Honors Scholarship, Edinboro University of PA 